\title{
John Doris' Excellence Adventure
}

Carrie Swanson

In his book Lack of Character (2002 Cambridge University Press) John Doris argues that both virtue ethics and common sense or folk psychology are committed to the claim that the attribution of character to persons is predictive, explanatory, and determinative of behaviour. Doris contends however that this claim is empirically false. Citing the results of experiments in the situationist research tradition in experimental social psychology, Doris argues that it is a person's situation, and not his or her character, that determines how a person will behave in a given situation. Doris concludes that virtue ethics in particular is in need of radical revision, since the attribution of character to persons is thereby shown to be otiose at best, and empirically misleading at worst. In this essay I defend traditional virtue ethics against Doris' situationist critique. My discussion falls into four parts. In Section 1 I set out the key claims that Doris makes about the empirical inadequacy of traditional virtue ethics. In Section 2 I describe three of the most important experiments which Doris adduces in his argument for situationism. In Section 3 I offer alternative interpretations of all three experiments, largely, but not exclusively, from an Aristotelian perspective. In Section 4 I respond to Doris' positive account of moral character, viz., his 'fragmentation hypothesis' and his theory of 'local traits'. Here I argue that Doris' positive account is lacking in explanatory power; I suggest as well that his positive account is poorly motivated, since he has largely misunderstood the traditional concept of a moral disposition. In particular, it is crucial to Doris' critique of virtue ethics that virtues and traits of character are cross-situationally consistent (or 'robust'); since according to Doris, it will only be attributions of character so conceived that are shown to be empirically inadequate by the situationist experiments he discusses. Doris' notion of a robust disposition is however alien to Aristotle and the virtue ethicists who are inspired by him. I demonstrate that the virtue ethicist conceives of a virtue as a rational disposition. A virtue is a disposition to act and feel in an appropriate way as a result of and in response to rational considerations about the good in particular circumstances. The acquisition of virtue is a difficult moral achievement because it involves the complex and interdependent development of both the intellectual and emotional capacities of a human being. It is precisely because the virtues are not robust traits in Doris' sense that the deliverances of practical reason, even when it is operating in its fullest capacity, will issue in decisions in particular circumstances that cannot be captured by the notion of 'cross-situational consistency'. I conclude that insofar as that is the case Doris has managed to make very little dialectical contact with the concept of virtue as that has been conceived in the virtue ethics tradition.

\section{$\S$ Introduction}

In his book Lack of Character John Doris argues that virtue ethics, as it has been traditionally conceived and practiced by moral philosophers, is empirically false, and should be replaced by a more empirically informed and empirically adequate theory of 
moral character. ${ }^{1}$ The trouble with virtue ethics as Doris sees it is this: the conception of a person's character that is central to a long philosophical tradition in virtue ethics is committed to the claim that if a person has a character of a certain kind, that character will have regular behavioural manifestations. So if we say that a person is temperate, or just, or courageous, we mean to imply that that person will regularly behave temperately, justly, or courageously in situations that require temperate, just, or courageous action. Similarly, Doris observes, our folk psychological attributions of personality traits are committed to making the same sort of predictive and explanatory claim: if Sam is talkative or boorish or absent-minded, Sam may be relied upon to exhibit talkative or boorish or absent minded behaviour in situations wherein talkative, boorish, or absent minded behaviour may be elicited, because he has the personality that he does.

Thus both virtue ethics and common sense or folk psychology, in their attributions of character to others, are committed to the claim that character is predictive, explanatory, and determinative of behaviour. But, Doris argues, there are many results of experiments in the situationist research tradition in experimental social psychology that suggest that this claim is empirically false. The situationist experimental record suggests that it is a person's situation, and not his or her character, that determines how a person will behave in a given situation. For example, the experimental record shows that whether or not a person finds a dime in the change slot of a pay phone prior to encountering a person who needs help is much more predictive of whether a person will help in that situation than any character trait that the person could be alleged to have. And if that is so, Doris argues, virtue ethics in particular is in need of radical revision, since the attribution of character to persons is thereby shown to be otiose at best, and empirically misleading at worst.

In this essay I attempt to defend traditional virtue ethics against Doris' situationist critique. I do so largely from an Aristotelian perspective, for two reasons. The first is that Aristotle's theory of moral virtue has inspired much of the work that is being done today in the field of virtue ethics. The second is that Aristotle's theory of moral virtue is a prime target of Doris' critique. My discussion falls into four parts. In Section 1 I set out the key claims that Doris makes about the empirical inadequacy of traditional virtue ethics. In

${ }^{1}$ Doris, J.M. 2002. Lack of character. Cambridge: Cambridge University Press. 
Section 2 I describe three of the most important experiments which Doris adduces in his argument for situationism. In Section 3 I offer alternative interpretations of all three experiments, largely, but not exclusively, from an Aristotelian perspective. Finally, in Section 4 I respond to Doris' positive account of moral character, viz. his 'fragmentation hypothesis' and his theory of local traits. I argue that Doris' positive account is lacking in explanatory power; I suggest as well that his positive account is poorly motivated, since he has largely misunderstood Aristotle's conception of a moral disposition. I conclude that insofar as that is the case Doris has managed to make very little dialectical contact with virtue ethics as that has been traditionally been conceived, especially insofar as this tradition has availed itself of Aristotle's notion of a moral disposition.

\section{$\S 1.0$ A 'globalist' conception of character}

Doris characterizes the virtues and other traits of character in terms of a number of other key concepts. Thus Doris assumes that virtues and traits are dispositions of a certain kind. It is crucial to Doris' critique of virtue ethics that virtues and traits of character are further assumed to be global traits, since according to Doris, it will only be globalist conceptions of character that are shown to be empirically inadequate by the situationist experiments he discusses. The notion of a global trait is defined in turn in terms of a number of other concepts, viz., consistency, stability, robustness, individuation, and inseparability — or as Doris puts it, 'evaluative integration.' In this section I will describe in some detail how Doris argues from the assumption that virtues and personality traits are global in his sense, to his conclusion that virtue ethics is empirically inadequate.

\section{$\S 1.1$ Doris on character}

According to Doris, the traditional moral virtues - e.g. justice, honesty, courageas well as personality traits such as shyness, impulsivity, and absentmindedness-are dispositions to behave in a certain way. 'To attribute a character or personality trait to someone is just to say that that person is disposed to behave in a certain way under certain 
eliciting conditions.' ${ }^{2}$ If that is so, Doris argues, then the attribution of a character trait to an individual will entail a conditional statement---a conditional statement that will be open to empirical assessment:

If $\mathrm{x}$ possesses character trait $\mathrm{C}$, then $\mathrm{x}$ will exhibit trait-relevant behaviour in trait-relevant eliciting conditions. $^{3}$

By 'trait-relevant eliciting conditions' Doris means the situation the person is in. As Doris acknowledges in his subsequent discussion, how we are to characterize an agent's situation requires quite a bit of sorting out: is the 'trait-relevant eliciting condition' a person is in to be described objectively, from an observer's point of view? Or is an agent's 'situation' determined, at least in part, by the person's subjective interpretation of his or her circumstances? ${ }^{4}$

For present purposes this question may be answered by noting how Doris responds to a possible objection to the dispositional treatment of traits of character. It seems, Doris concedes, that in certain cases the conditional entailed by an attribution of character will be false. Such cases will involve a kind of 'masking' phenomenon, where one dispositionto friendliness say — is present together with a countervailing disposition — say, to crippling shyness. According to Doris, it is therefore possible that two traits may be elicited by what he calls 'identical circumstances', where the one trait is always trumped or silenced by the other.

Here it is fairly clear that what Doris takes to be 'identical' in these eliciting circumstances is going to be objectively determined, e.g., by the fact that there are a certain number of people in the room. For he argues that if an agent's disposition to friendliness is

\footnotetext{
${ }^{2}$ Doris (2002), 15.

${ }^{3}$ In using the terms 'traits' or 'dispositions' I will sometimes not distinguish between moral character traits and personality traits. Doris assumes that his main arguments apply to both; however, I am mainly concerned in what follows with his discussion of the moral character traits that are traditionally of interest to virtue ethicists.

${ }^{4}$ For example, if $\mathrm{x}$ finds a $\$ 100$ dollar bill on the floor in a department store, is that a circumstance that is relevant to the trait of honesty? Is it an 'honesty-eliciting circumstance'? That might depend on the subject's interpretation or subjective construal of the circumstance, not on the observer's. This sort of consideration is also advanced by G. Sreenivasan (2002), 58.
} 
invariably and repeatedly blocked by his shyness in the very same circumstances, then we will be warranted in withdrawing the attribution to him of a disposition to friendliness. ${ }^{5}$

\section{$\S 1.2$ Doris on virtue}

Having claimed that virtues are dispositions to behave in certain ways under certain kinds of circumstances, Doris adds that the virtues of character, or at any rate those that are typically discussed by moral philosophers, are not just behavioural dispositions. 'Talk of traits as dispositions risks vacuity if it provides explanations no more enlightening than "he acted in this manner because he has dispositions to behave in this manner". ${ }^{6}$ What must added, Doris suggests, is that the overt behaviour of a virtue has a kind of dispositional base in an agent's motives and emotions. Doris seems to allow that such an 'internal' base of a behavioural moral disposition will include the agent's emotional dispositions, his or her patterns of beliefs and desires, and even cognitive capacities such as a reliable sensitivity to the ethically salient properties of the agent's situation. ${ }^{7}$

Nevertheless, although Doris appears to concede in passing that such internal cognitive and desiderative states are of considerable importance to what has traditionally been thought to come into the account of the virtues of character, he expresses little interest in the significance of this claim to virtue ethics. Doris does not pause to inquire what might be meant by these claims, or why they might be true or important to our conception of the virtues. Rather, having duly recorded that virtue ethicists do maintain that there are cognitive and emotional and desiderative components to virtue, what really matters - what is 'of central interest'---is behavioural output. ${ }^{8}$

${ }^{5}$ Ibid.16. Doris explicitly concedes that the situationist experiments he subsequently discusses construe a person's 'situation' objectively in the course of his consideration of social-cognitive theory as an alternative to his interpretation of the experiments: 'The experiments considered so far focus on 'nominal' features of situations: actor-independent features like dimes, group sizes, etc.' Cp. 76-80.

${ }^{6}$ Ibid. 16.

${ }^{7}$ Here Doris is thinking of McDowell's (1979) notion of such a cognitive capacity as a kind of moral perception.

${ }^{8}$ Ibid. 17. 
Thus Doris barely mentions in passing that Aristotle, and the virtue ethicists who are inspired by him, hold that virtue involves deliberation about the good. In fact, Doris only comes close to mentioning this fact in a footnote. Here Doris does manage to make a reference to deliberation; but he never brings the notion of the good into Aristotle's picture. This is what he says: 'The emphasis on deliberation is evident in Aristotle, as is the emphasis on emotion. ${ }^{9}$

But of course for Aristotle, deliberation about the good is the sine que non of the possession of a virtue of character. ${ }^{10} \mathrm{~A}$ virtue is a rational disposition, one that issues in a practical decision about the good; a virtue is a disposition to act and feel in an appropriate way as a result of and in response to rational considerations about the good. I shall argue below that since the traditional notion of virtue as a rational disposition never makes its way into Doris' characterization of virtue ethics, Doris' argument manages to make little, if any, dialectical contact with the theory of virtue ethics that he takes to be his target. For our present purposes, however, we may simply observe that Doris construes a virtue to be a certain disposition to behave in certain ways, ways that happen to be related, perhaps in a complex fashion, to certain other internal states that the agent happens to be in. ${ }^{11}$

That Doris takes a virtue to be a non-rational behavioural disposition also seems clear from his interpretation of Aristotle's thesis that the virtues are states (hexeis).

${ }^{9}$ Ibid. $175, \mathrm{n} .8$. It is clear from the same note that Doris believes that he can discuss Aristotle's theory of moral virtue without discussing his theory of the intellectual virtue of practical reason. 'The picture is complicated by Aristotle's distinction between ethical virtue and intellectual virtue...but this won't much trouble me here.' Doris should be troubled. I will suggest below that his argument against traditional virtue ethics is largely vitiated by his disinterest in Aristotle's 'expectation.... of some integration' (as Doris puts it) between practical wisdom, (phronêsis), understanding (nous), and the virtues of character.

${ }^{10}$ See especially NE VI.13 1144b30-45a5.

${ }^{11}$ Doris insists that 'accounts of virtue emphasizing 'internal' processes are best understood as complements, not competitors, to characterizations emphasizing behavioural dispositions, inasmuch as they explicate the psychological processes subserving behavior', 17. Then he notes that McDowell maintains that virtue's 'perceptual capacity' produces, and hence explains, the virtuous person's behaviour. But neither McDowell nor Aristotle mean that the kind of 'perceptual capacity' that characterizes the phronimos, or the man of complete virtue, is merely a complement to his virtue. It is rather a necessary condition of being fully virtuous that such a sensitivity to the particulars of a situation be integrated into the exercise of the agent's practical wisdom. Since Doris does not grasp this point he is lead to construe the virtue of the phronimos as a certain disposition to behave in certain ways, despite his concession that the virtuous agent's action involves 'internal processes' that 'subserve' his or her behaviour. 
Aristotle argues that the moral virtues are settled states or dispositions of the soul that are permanent or at least exceedingly difficult to change. ${ }^{12}$ As Doris sees it, this underscores the fact that the virtues are primarily behavioural dispositions: the attribution of a virtue to a person, on the assumption that a virtue is a hexis, is supposed to provide us with both positive and negative assurance: the virtuous person will execute such and such behaviour unfailingly whenever behaviour of that sort is required by his or her circumstances; and the virtuous agent will always refrain from performing actions that are contrary to virtue, no matter what the inducements and temptations may be in the agent's situation to do otherwise. $^{13}$

Doris concludes, on the basis of a very brief (one and one half page) survey of the history of virtue ethics that the virtues as they have been traditionally conceived are 'robust' traits, which exhibit 'behavioural consistency'. By a virtue being a 'robust' trait, Doris means this:

If $\mathrm{x}$ has a robust trait then $\mathrm{x}$ can be confidently expected to display trait-relevant behaviour across a wide variety of trait-relevant situations, even where some or all of these situations are not optimally conducive to such behaviour. ${ }^{14}$

We need to understand what Doris means by the 'variety' of trait-relevant situations he refers to here; and we need to understand what he means by his condition that the situations may not be 'optimally conducive' to the trait-relevant behaviour. We also need to ask whether Doris takes the notion of robustness to be partially defined in terms of the notion of consistency, or whether he takes consistency and robustness to be two separate properties of traits.

Unfortunately it is not clear upon first reading how Doris means to be using these terms. How his definition of robustness, for example, is supposed to fall out of his discussion of virtue as a hexis is rather obscure. Indeed by the time he summarizes his notion of a global trait at the end of his second chapter, his notions of robustness and

12 Cat. 8b25-9a9; cp. NE 1100b12-24; 1105a30-b1; 1114a10-24; 1152a30-32. While becoming virtuous is a difficult achievement, once attained the state of virtue is durable; in particular the virtues persist despite the loss of goods due to misfortune. On this point see Irwin (1985).

${ }^{13}$ Doris (2002), 17-18.

${ }^{14}$ Ibid. 18. 
consistency seem to have changed places: at the end of the chapter he seems to define robustness in terms of consistency, and consistency in terms of another notion which he calls 'stability'; but he seems to at least partially gloss the notion of robustness in terms of stability in a lengthy footnote. ${ }^{15}$ Matters are somewhat clarified by two further notes he provides to his subsequent discussion of the unity (or 'evaluative integration') of the virtues. ${ }^{16}$ It eventually becomes clear that Doris does mean to define robustness in terms of the notion of consistency; but a virtue will be robust only if it produces behaviour of the same type, across diverse circumstances.

So robustness is a kind of cross-situational consistency. The point of Doris' inclusion of the condition that for robustness to obtain, some of these situations may not be 'optimally conducive' to the trait-relevant behaviour is then just this: in order to attribute a robust trait to an agent, the situation the agent is in has to be unfavorable enough to the trait-relevant behaviour in question so that the behaviour the allegedly virtuous agent displays is better explained by reference to his individual disposition to virtue than it would be by reference to merely situational factors. For example, if everyone always puts money in the collection box every Sunday morning, that is not sufficient evidence to attribute the virtue of charity to any one of the congregates. But if there are other charity-relevant situations that this same population encounters, over which their charity-relevant behaviour varies markedly, where only a few individuals for example consistently display charitable behaviour, then Doris' claim is that those situations are diagnostic for the virtue of charity; since it seems we can better explain the behaviour of these few congregates in terms of their behavioural dispositions, rather than the situations they find themselves in.

That brings us back to Doris' notion of stability. The stability of a character trait is also a kind of consistency, but here it is a consistency across similar trait-eliciting circumstances. Thus putting money in the collection box every Sunday is an example of the stability of charity; never exceeding one's two-martini limit at cocktail parties is an example of the stability of moderation. Doris maintains that robustness entails stability: if a character trait is robust enough to secure consistent behaviour over trials of dissimilar

${ }^{15}$ Ibid. n. 16, 176.

${ }^{16}$ Ibid. n.35 and n. 40, 178-79. 
situations, it will undoubtedly secure consistent behaviour over trials across similar situations.

\section{$\S 1.3$ Doris on Personality Traits}

Here I will be very brief, since the properties of robustness and stability that virtue theorists have traditionally attributed to the virtues are also, Doris thinks, presupposed to hold of the personality traits by the personality psychologists who have studied them. Doris does draw our attention to a couple of interesting and possibly important differences between the virtues and 'generic' personality traits. First, the virtues obviously have an evaluative dimension that not all personality traits have. This seems to be true both from the observer's point of view and from the point of view of the agent. Thus we seem both to describe and evaluate an agent in calling her courageous; but an introvert in describing herself as such may remain evaluatively neutral on the desirability of her retiring behaviour; on the other hand, she may mean to express her own disapproval of her behaviour in describing herself as shy.

Doris also notes that there may be a difference in the degree of consistency that we typically expect from the virtues as opposed to mere personality traits. That is to say, we may expect more cross-situational consistency from a virtuous agent than we do from a gregarious, agreeable, or introverted agent. He concedes too that even among the virtues there may be different degrees of expected consistency. We may have higher standards for the attribution of courage and loyalty than we do for compassion: one or two failures to behave courageously when courage seems called for may induce us to withdraw our attribution of courage to an agent; whereas we may not expect a person to behave compassionately on every occasion where an opportunity to behave compassionately arises. Doris does not have much to say about what may explain these facts - though such an inquiry would seem to be relevant to an explanation of some of the experiments he will discuss. $^{17}$

${ }^{17}$ I am thinking in particular of course of the Princeton Theological Seminary experiment, which I discuss below, 13-15, 18-34. 
In the end however, Doris says these sorts of issues do not matter for the purposes of his argument, since he is not out to show that there is some single standard of consistency that any or all attributions of either virtue or personality traits must meet. His point rather is that the experiments he discusses disclose a marked disparity between the extent of consistency that we might expect from the attribution of any one given trait or virtue, and the extent of the behavioural consistency that the experiments suggest we are justified in expecting from agents.

\section{$\S 1.4$ Doris on the Unity of Virtue}

Doris next takes up the issue of the inseparability of the virtues. This is the notion that in some way or other the possessor of any one virtue must be morally sensitive to the requirements of what all the other virtues may require in a given situation. We may point to Plato's Euthyphro (though Doris does not) as a familiar example of a virtue ethicist's exploration of this topic. Euthyphro is happily on his way to prosecute his own father for manslaughter when we meet him at the beginning of the dialogue. Socrates is shocked: he thinks Euthyphro's grasp of what the virtue of justice requires is horribly out of tune with his grasp of what the virtue of piety demands.

As Doris notes, the thesis that each of the virtues must be in some way sensitive to the demands of all the others has been given stronger and weaker interpretations in the virtue ethical tradition. The strongest thesis is the identity thesis-sometimes called the unity thesis. This is the claim that all the virtues are strictly identical (Socrates as portrayed in Plato's Protagoras may be construed as holding this view); ${ }^{18}$ another way of putting the same idea is that the virtues are all manifestations of a 'single complex sensitivity' (a view which Doris attributes to McDowell). ${ }^{19}$

\footnotetext{
${ }^{18}$ In his classic treatment of the subject, Penner (1973) argues that Socrates defends the identity thesis in the Protagoras.

${ }^{19}$ McDowell (1979). See also McDowell (1998), 111: 'Having the right conception of the end is, at least, a state of one's motivational susceptibilities.'
} 
A weaker version of the inseparability thesis would be Aristotle's equivalence or reciprocity view: this is the claim that a moral agent has one of the virtues just in case the agent has all of them. ${ }^{20}$

A still weaker account of inseparability would maintain only that genuine virtues and vices cannot coexist within a single agent, since genuine virtue would entail evaluative commitments that would exclude the claims of vice. An even weaker version of inseparability is one that Doris says will inform his own positive account of character. This is the view that virtues within a given practical domain are inseparable - in the sense of reciprocal now - but that the virtues are separable across different domains of practical endeavor. Thus the faithless husband can be an upstanding public servant, since the domains of marriage and politics are so distinct; but we would expect much greater integration within a single domain; the scholar must be both diligent and honest with respect to her work.

\section{$\S 1.5$ Doris' thesis: the global nature of character traits}

Having completed his survey of traditional virtue ethics and the study of personality, Doris sums up his findings under the heading of three main presuppositions that he thinks all these theories have made about the notion of character:

(1) Consistency (i.e. robustness): Character and personality traits are reliably manifested in traitrelevant behavior across a diversity of trait-relevant eliciting conditions that may vary widely in their conduciveness to the manifestation of the trait in question.

(2) Stability: Character and personality traits are reliably manifested in trait-relevant behaviors over iterated trials of similar trait-relevant eliciting conditions.

(3) Evaluative integration: in a given character or personality the occurrence of a trait with a particular evaluative valence is probabilistically related to the occurrence of other traits with similar evaluative valences. ${ }^{21}$

Taking (1)-(3) together, Doris concludes that the virtue ethical tradition is committed to a thesis which Doris calls globalism. Globalism construes personality or character as an evaluatively integrated association of robust traits. With respect to the

${ }^{20} N E$ VI.13 1144b30-45a5.

${ }^{21}$ Doris (2002), 22-23. 
logical relationships that obtain between (1), (2) and (3), Doris maintains that neither (1) consistency/robustness, nor (2) stability entails (3) integration. ${ }^{22}$ Moreover, Doris denies that the stability of a trait entails consistency or robustness. The significance of this latter assumption becomes apparent in Doris' subsequent positive account of traits of character. Doris will eventually endorse a form of stability for character traits while rejecting their robustness and integration: he will argue that while we have to reject the conception of robust traits such as courage or honesty, we can nevertheless replace such 'globalist' attributions with attributions of extremely fine-grained 'local' traits such as gun-battle-butnot-knife-fight-courage; or helping-in-situation-of-type1-but-not-helping-in-situation-oftype2 compassion. Such traits will obviously be highly 'stable', in Doris' sense, across highly similar situations.

The main thesis of Lack of Character then is that globalism with respect to character traits is false. This is because the globalist conception of character presupposes the existence of substantial behavioural consistency where none has been empirically demonstrated. It is Doris' view that it is situationist social psychology that has revealed this fact to us. Doris takes the three central theoretical commitments of situationism to be the following:

(1) Behavioural variation across a population owes more to situational differences than to dispositional differences among persons. In fact, it will turn out that it is safest to predict for a particular situation that a person will behave in a fashion similar to the population norm.

(2) The attribution of robust traits to individuals is problematic, since people will typically behave inconsistently with respect to the attributive standards associated with a trait; moreover whatever cross-situational consistency is displayed may be easily disrupted by situational variation. Thus while the stability of traits is well marked, the robustness of character traits is not.

(3) Personality is not evaluatively integrated. Evaluatively inconsistent dispositions are often found to be exhibited by a single person from situation to situation. ${ }^{23}$

The situationist theses entail a rejection of a globalist conception of character, since they reject the globalist theses of robustness and integration. On the other hand, situationism allows that the stability of traits is, after a fashion, empirically verifiable, since

\footnotetext{
${ }^{22}$ This will certainly seem to be true if the identity thesis is denied; but not otherwise.

${ }^{23}$ Doris (2002), 24-25.
} 
situationist experiments demonstrate that subjects will exhibit behavioural consistency over repeated trials of substantially the same situations.

\section{$\S 2.0$ The Experiments}

Doris basis his critique of virtue ethics on his interpretations of a number of wellknown experiments in the situationist social psychology tradition. In this section I will briefly describe three of the most important of these experiments, and in each case, explain how Doris' interpretations are alleged to further his situationist analysis of character.

\section{§2.1 Princeton Theological Seminary Study}

The subjects of this experiment were Princeton Theological Seminary students. ${ }^{24}$ Students were asked to provide self-descriptions (interested in religion as an end in itself, as means to salvation, as a search for the meaning of life, to serve others, etc.) which were subsequently taken to constitute the character variable of the experiment. All subjects were then invited to participate in a seminar related to the vocational opportunities for seminary students. The first 'situation' variable of the experiment was whether subjects were asked to read the parable of the Good Samaritan (Luke 10:30-37), or whether they read a brief essay about new vocational alternatives for those entering the ministry. After completing their various readings, all subjects were then told that they had to give a talk (a potentially nervous-making affair, the more so because they were told the talk would be 'recorded') in a different location on the campus. The second situation variable was the amount of time the subjects were told they had to reach the venue in which they were to deliver their talks. Some subjects were told by the experimenters that they should hurry, because they were already late; others were told they would be right on time if they left immediately; still others were told they had some time to kill (a few minutes) before they were expected. On

\footnotetext{
${ }^{24}$ It is recounted in Darley, J.M., and Batson, C.D. (1973), reprinted in Elliot Aronson (1992). My page references are to the latter.
} 
their way to the new venue each seminarian encountered an experimental confederate 'victim':

When the subject passed through the alley, the victim was sitting slumped in a doorway, head down, eyes closed, not moving. As the subject went by, the victim coughed twice and groaned, keeping his head down. If the subject stopped and asked if something was wrong or offered to help, the victim, startled and somewhat groggy, said, "Oh, thank you [cough]...No, it's all right. [Pause]. I've got this respiratory condition [cough]...The doctor's given me these pills to take, and I just took one...If I just sit and rest for a few minutes I'll be O.K...Thanks very much for stopping though [smiles weakly]." If the subject persisted, insisting on taking the victim inside the building, the victim allowed him to do so and thanked him. ${ }^{25}$

Darley and Batson found no correlation between helping behaviour and the students' stated religious goals. They did however find a strong correlation between helping behaviour and the second situational variable. Help was offered by only 40 percent of all subjects (sixteen of the forty seminarians). Of those seminarians who believed they had time to kill, 63 percent helped, as well as 45 percent of those who believed they were 'right on time.' On the other hand, only 10 percent of those who believed they were late assisted the victim. Little correlation was found between helping behaviour and the first situational variable. While 53 percent of subjects who read the parable of the Good Samaritan helped, Darley and Batson concluded that only hurry was a significant predictor of whether one will help or not. ${ }^{26}$

Doris does not suggest that the situationist moral of the seminarian study is merely that being in a hurry can cause people to pay less attention to their fellow human beings. As Doris sees it, the significance of the experiment lies rather in 'the apparent disproportion between the seriousness of the situational pressures and the seriousness of the omission [i.e. of helping behaviour].' What is 'surprising... is that the thought of being a few minutes late was enough to make subjects not notice or disregard a person's suffering.' Given this 'appearance of disproportion', Doris finds it implausible to interpret the subjects' behaviour by suggesting that any felt obligation to help the experimenters was 'trumping' any felt obligation to help the victim; for 'in this case the demands of punctuality seem rather slight compared with the ethical demand to at least check on the condition of the

\footnotetext{
${ }^{25}$ Ibid. 43-44.

${ }^{26}$ Ibid. 45-49.
} 
confederate. ${ }^{27}$ Doris also seems to find it an aspect of the 'disproportionality' of the experimental results that individuals who were training for a 'helping profession' such as the ministry, whom we might expect to be disposed to caring behaviour, could instead be led by so slight a situational factor as being late to exhibit insensitive, or even callous, behaviour, instead. ${ }^{28}$

Doris acknowledges that, since Darley and Batson did not collect longitudinal data on the subjects of the experiment, the study can tell us nothing about the characterological consistency of the particular individuals who were the subjects of the experiment. Nevertheless, Doris argues, given the experimental results, the situationist may argue indirectly to the absence in the general population of character traits that exhibit a high degree of cross-situational consistency. For according to Doris, the experiment shows that it is the situation, not a person's alleged traits of character that has a powerful determinative effect on behaviour. Since it is safe to assume that people will typically encounter situations that differ markedly in their levels of conduciveness to helping behaviour, we may anticipate that people will typically exhibit little cross-situational consistency with respect to the virtue of compassion. But if that is so, we may safely deny that there exists any such global trait as 'compassion', which manifests itself in a high degree of cross-situationally consistent behaviour. ${ }^{29}$

\section{$\$ 2.2$ The Milgram Experiments}

Subjects agreed to take part in a study on learning and memory which involved word-matching questions put to 'learners' (in fact confederates of the experimenter). ${ }^{30}$ The subject 'teachers' were instructed by an experimenter in a lab coat to administer electric shocks (described as 'painful', but not such as to cause 'permanent tissue damage'), to the learners, in fifteen-volt increments, for every incorrect answer; a failure to respond to a question was also counted as a wrong answer. The teachers were situated in a room apart

\footnotetext{
${ }^{27}$ Doris (2002), 34.

${ }^{28}$ Ibid. 34.

${ }^{29}$ Ibid. 38-39.

${ }^{30}$ Milgram, S. (1963).
} 
from the learners and seated in front of an impressive looking 'shock generator', complete with voltage indicators ('75: moderate shock'; '375: danger: severe shock') which the teachers were told were wired to electrodes on the learners. (In fact the shocks were fake.) By prearrangement, the learners responded 'incorrectly' on a gradual schedule, so that the intensity of the shock administered by the subjects was steadily increased. If at any point the subjects hesitated and expressed concern for the learners, the experimenter responded each time with one of a graduated series of verbal prods. ('Please continue'. 'The experiment requires that you continue.' 'It is absolutely essential that you continue.' 'You have no other choice, you must go on.') If the teachers refused to continue after the final prod, the experiment was terminated and the subject was counted as 'disobedient.' Those teachers who complied with all the experimenter's commands until the maximum shock level was reached were counted 'obedient.'

In the original version of the experiment, the confederate learner demanded to quit at the 150-volt level. ('That's all! Get me out of here!') At the 300-volt level ('extreme intensity shock'), the confederate emitted play-acted but convincing screams of agony, pounded on the wall, and demanded that the experiment be terminated. At 330 volts, the confederate was completely unresponsive---suggesting that he could be too helpless to respond. Subjects who hesitated to administer pain at this point were reminded that nonanswers were 'wrong' answers, and urged to continue to the next increment of shock level. The results of the Milgram experiments are, to say the least, unsettling. In various permutations of this basic scenario, Milgram found that fully two-thirds of the subjects were obedient, continuing to administer shocks until the highest level of pain ('XXX') was reached, where the 'learners' had lapsed into ominous silence, the result of their having (presumably) been completely incapacitated by severe electric shock.

Doris agrees that the results of the Milgram experiments are surprising and disturbing. But he denies that they demonstrate that human beings are blindly obedient to authority. ${ }^{31}$ In fact, Doris thinks it is important to draw attention to the fact that most subjects of the Milgram experiments felt severe emotional conflict, even as they continued to administer shock after shock. ('The most striking feature of the demonstration is not

${ }^{31}$ Doris (2002), 39. Evidently this is the conclusion that many commentators have wished to draw from the experiments. Doris cites D.J. Goldhagen (1996) in this regard. 
blind obedience, but conflicted obedience'). ${ }^{32}$ Neither does he wish to infer, from the subjects' apparently callous behaviour, that the subjects were disposed to display insensitive behaviour whenever given the opportunity to do so. ('Trait-contrary behavior does not necessarily signal the possession of a contrary trait'). ${ }^{33}$

On the contrary, since the 'teachers' in the Milgram experiments were presumably ordinary folks, not sadists, Doris suggests that the proper lesson to draw is the situationist one: the study shows how subtle situational factors may induce or facilitate behavior that is obviously contrary to a person's normal evaluative dispositions. Since there is no reason to think that individual differences in character are responsible for whether a subject in a Milgram experiment is disobedient or not, it is reasonable to conclude that there is no such thing as a disposition to compassionate moral behaviour that is robust in Doris' sense - an interpretation that would only seem to be strengthened by the results of various permutations of the experiment, wherein different levels of obedience were easily produced by manipulating different features of the situation. (For example, it proved easier for subjects to harm a learner whom they could not see or hear, harder to harm a learner whom they had to touch; and it was easier to inflict 'indirect' harm, e.g. when subjects were instructed only to perform tasks subsidiary to administering the shocks). ${ }^{34}$

\section{$\S 2.3$ Mood Effects: A Dime's Worth of Difference}

In this experiment, subjects were instructed to make phone calls in public pay phones in shopping malls. ${ }^{35}$ The situational variable was that some subjects found a dime in the pay phone coin return slot that had been planted there by the experimenters. Other subjects did not. As the subjects exited the phone booths, an experimental confederate walked across their path, and 'accidentally' dropped an armful of papers. Of the sixteen

\footnotetext{
${ }^{32}$ Ibid. 39.

${ }^{33}$ Ibid. 39.

${ }^{34}$ Ibid. 46.

${ }^{35}$ Isen, A.M., and Levin, P.F. (1972).
} 
subjects who found a free dime, fourteen stopped to help the confederate pick up the papers; only two did not. Of the twenty five subjects who did not find a dime, only one helped.

In the case of the Good Samaritan study, the situationist point was not merely that a feeling of being hurried can effect behaviour. So too in the case of this experiment, Doris insists, the point is not merely the obvious fact that mood can influence behaviour. The 'crucial observation' rather is the disproportionate effect on behaviour of a minor aspect of the situation: it is the unobtrusiveness of finding the dime, versus the massive difference in determining behavioural outcomes that once again points the situationist moral. Fully ninety-six per cent of non-finders failed to help. It therefore makes no sense to suppose only subjects blessed with the robust disposition of compassion lucked into finding the dime. Rather, the best explanation for helping was that a subject found a dime - an entirely non-characterological situational factor. ${ }^{36}$

\section{$\S 3.0$ The Experiments Reconsidered}

A number of objections may be raised to Doris' interpretations of the situationist studies. Some of these misgivings concern particular inferences Doris makes in the course of discussing each experiment. Others concern particular assumptions Doris makes with regard to some of the key concepts in the virtue ethical tradition that he targets for refutation. In this section I will discuss problems arising from both of these sources, in regard to each of the experiments above.

\section{$\S 3.1$ Running the Samaritan Gauntlet}

As we noted above, Doris deems one aspect of what he calls the 'disproportionality' of the seminarian experiment to be the fact that individuals who were training for a 'helping profession', whom we might expect to be disposed to caring behaviour, could instead be induced to exhibit insensitive or callous behaviour by so unobtrusive a situational factor as being late to give a talk. The assumption that seminarians could be expected to be disposed to helping does seem rather quaint from our

${ }^{36}$ Doris (2002), 30. 
(possibly jaundiced) contemporary perspective on this particular profession. But surely it is just as true today as it was in the 1970's that people enter the ministry for a variety of reasons (e.g., because of the sense of power it may yield, for a sense of safety from troubling emotional or intellectual doubts, to avoid military service, to please one's parents, etc.)---many of which have no implications for a disposition to compassion. ${ }^{37}$

Doris acknowledges Owen Flanagan's criticism that we are therefore unjustified in the assumption that seminarians are more compassionate than the general population. ${ }^{38}$ However, he insists that the profession of the subjects in Darley and Batson is still 'of general relevance' unless we have some reason to suppose that hurried seminarians are less disposed to helping behaviour than the general population. ${ }^{39}$ It is however unclear why Doris feels that he is entitled to make this claim, when it is obvious that we have no reason to suppose that seminarians are either more or less disposed to compassion than people in general.

On the other hand, we might have some reason to suppose that these particular hurried seminarians would be less disposed to helping behaviour than hurried people in general, if Darley and Batson had recorded the ages of the participants in the study. ${ }^{40}$ Virtue ethicists typically claim that the acquisition of a reliably virtuous disposition is a difficult achievement, which comes only with experience and wisdom. ${ }^{41}$ Plato's philosopher-kings must complete a rigorous fifty-year educational program before they are allowed to rule. Aristotle observes that young people are not disposed to virtuous activity because, lacking experience in practical reasoning and the contingencies of moral action, they are typically led by their momentary emotions instead of their all-things considered-judgments about

${ }^{37}$ I once had a friend (now sadly dead) who entered an Episcopalian seminary at the age of fortythree. His motivation was (as he put it) 'to cure myself of the desire to fuck other men.' He claimed that over seventy-five percent of his fellow seminarians had joined the ministry for the same reason. When I expressed skepticism on this score-'how could you possibly know that?'- he replied, 'Because we had to hear each other at confession'---conversations which he could only describe as 'absolutely heartbreaking.'

${ }^{38}$ Flanagan (1991), 301-2.

${ }^{39}$ Doris (2002), n. 20,183.

${ }^{40}$ It seems clear from Darley and Batson (1973) that this was not done.

${ }^{41} N E$ 1143b5-16; cp. 1142a12-20. 
the good. ${ }^{42}$ If feeling hurried counts as a momentary emotional state, and if the graduate students in Darley and Batson were typical with respect to their age, then the results of the study would be precisely predicted by the virtue ethical tradition.

It seems probable that Doris would make the following rejoinder to the foregoing observations about the subjects' possible inexperience in what Aristotle would call 'the actions of life': the experiment revealed a disproportion between the relative unimportance of the situational pressure (of hurry) and the seriousness of the omission of helping behaviour. 'The thought of being a few minutes late was enough to make subjects not notice or disregard a person's suffering. ${ }^{43}$ It was obvious that the 'victim' in the experiment needed help. Even a graduate student, endowed with only the rudiments of the robust trait of compassion, ought to have been able to work out that there was a moral imperative to at least check on the condition of the confederate.

Such a response however would seem to ignore the distinction between the subjective states of those subjects who seemed to have failed in some morally significant sense to perceive the victim as in need of help, and those who seemed to take in this fact but disregarded it anyway. As Darley and Batson observed, almost all the seminarians in a post-experiment interview seemed to have noticed the victim in the sense that they were retrospectively aware of him as someone who, on reflection, could possibly have been in need of aid. But with respect to some of the subjects who did not stop, they observed that [...] it seems that they had not worked this out when they were near the victim. Either the interpretation of their visual picture as a person in distress or the empathic reactions usually associated with that interpretation had been deferred because they were hurrying. According to the reflections of some of the subjects, it would be inaccurate to say that they realized the victim's possible distress, then chose to ignore it; instead, because of the time pressures, they did not perceive the scene in the alley as an occasion for an ethical decision. ${ }^{44}$

Now if that is so, then we do have evidence that these subjects at any rate (as well as the subjects who did stop to help) were presumably capable of expressing-

${ }^{42} N E$ 1095a2-14; 1150b25-29; 1156a30-b4.

${ }^{43}$ Doris (2002), 34.

${ }^{44}$ Darley and Batson (1973), 50. It seems significant in this regard to note that (as may be inferred from the account cited above of the 'victim's' pre-arranged scripted behaviour), the confederate was careful not to initiate any eye-contact with the students as they walked past. 
retrospectively, at least - the internal states (the appropriate beliefs, desires, and emotions) which the virtue ethical tradition would deem necessary conditions to an act's issuing from a disposition to compassionate behaviour. ${ }^{45}$ What seems to have happened in their case is that the situational variable of being hurried caused a diminution in the moral salience of the victim's need. Perhaps then the defender of virtue ethics should concede that whether a person helps or not on the basis of an instantaneous decision is likely to be situationally sensitive, but insist that perceiving a situation as requiring an ethical decision in the first place falls outside the scope of any moral disposition? ${ }^{46}$

But of course the virtue ethicist will and should be tempted by only half of this suggestion. It is at any rate essential to Aristotle's theory of moral knowledge that perceiving a situation as falling under an ethically relevant universal is partly constitutive of the possession of a virtue of character. ${ }^{47}$ For reasons that I will sketch in more detail below, Aristotle insists that moral action begins in the correct perception of morally relevant particulars (where this involves seeing them as falling under universals - e.g., 'the fine', 'the just'). ${ }^{48}$ However, this requirement simply underscores the point made above about the fact that virtue is a difficult achievement, and requires a great deal of practical experience. As Aristotle says (speaking of the internal or emotional component of virtue):

${ }^{45}$ Burnyeat (1980) is a classic treatment of Aristotle's account of how such proper emotional responses are acquired through habituation. Lawrence (2011) offers a more recent exhaustive account of the interpretative issues involved in Aristotle's views on the acquisition of virtues of character.

46 As Darley and Batson conclude (50), whether a person helps or not on the basis of an instantaneous decision is likely to be situationally controlled; but how they go about helping, once they have decided to help, may be due more to a person's individual character. Their results evidently did show some correlation between the type of religiosity a subject expressed (which was taken to constitute the character variable of the experiment) and how (helping) subjects helped.

${ }^{47} \mathrm{Cp}$. $N E$ 1141b14-20: 'Nor is practical wisdom concerned with universals only-it must also recognize the particulars; for it is practical, and practice is concerned with particulars. This is why some who do not know, and especially those who have experience, are more practical than others who know; for if a man knew that light meats are digestible and wholesome, but did not know which sorts of meat are light, he would not produce health, but the man who knows that bird-meat is wholesome is more likely to produce health.' See also 1142a12-20, 1142a23-30, and 1143a35b14.

${ }^{48}$ Cp. Reeve (1992), 67-79; Tuozzo (1995). On the scope and moral significance of Aristotle's notion of 'the fine' (to kalon) see Lear (2009). 
It is possible on occasion to be affected by fear, boldness, appetite, anger, pity, and pleasure and distress in general both too much and too little, and neither is good; but to be affected when one should, at the things one should, in relation to the people one should, for the reasons one should, and in the way one should, is both intermediate and best, which is what belongs to excellence' [i.e., virtue, aretê]. (NE II.6 1106b18-23).

Again, speaking of virtuous action in general, he says:

This is why being excellent is also something difficult to achieve. For in any context getting hold of the intermediate is difficult - as for example finding the center of a circle is not a task for anyone, but for the skilled person; so too, whereas getting angry, or giving money away, or spending it are things anyone can do, and easy, doing them to the person one should, to the extent one should, when one should, for the reason one should, and in the manner one should - this is no longer for anyone, nor is it something easy, which explains why getting things right is a rare thing, a proper object of praise, and something fine. (NE II.9 1109a24-30).

I will presently comment on Aristotle's famous 'doctrine of the mean' that is implicit in these two passages. Prescinding for the moment from the details of that doctrine, what these texts suggest is that whether an agent does correctly grasp the morally salient particulars of his or her situation is indeed massively situationally sensitive; but that with the proper experience and disciplined alignment of one's beliefs, desires, and emotions, one can nonetheless greatly improve one's ability to see through the situational 'noise' and respond, both emotionally and behaviourally, in the morally appropriate way.

Thus according to the virtue ethical tradition, at one end of the scale of virtuewhere in fact, according to Aristotle, most of us decent, but self-absorbed folk are stuck--people will tend not to notice the needs of their fellow human beings if they are in a hurry unless it is glaringly obvious that help is required. ${ }^{49}$ (Imagine the Darley and Batson experiment resurrected more along the lines of the original story of the Good Samaritan: on their way to their talks, the subjects witness a violent mugging or attempted rape in the near distance. The screaming victim is beaten, for all appearances, within an inch of her life and stripped of her clothing, until the aggressor senses the approach of the subject, when he flees. Would more hurried seminarians stop to help than stopped in the original study?) At the other end of the scale of moral excellence - a position which few people occupy, according to Aristotle - the man or woman of complete practical wisdom will be

49 Texts where Aristotle comments on the fact that the majority of people fall short of complete excellence include NE I.9 1099a10-15; VII.7 1150a10-14; VII.10 1152a25-30. 
reliably sensitive to ethically relevant details of a situation that will escape the notice of almost anyone else. (Of all the characters in the novel, it is only Huck Finn, the moral witness of the tale, who habitually perceives his surroundings as a moral landscape: gazing 'away down into' a village from a hilltop late at night Huck sees not merely lights and water, but 'three or four lights twinkling, where there was sick folks, may be; and the stars over us was sparkling ever so fine; and down by the village was the river, a whole mile broad, and awful still and grand. ${ }^{50}$ )

In between these two extremes it is possible for a moral agent to extend indefinitely his or her grasp of what acting in accordance with virtue may require. But then given that the perception of what virtue requires $i$ s situationally sensitive for these reasons, correctly interpreting a situation as requiring compassionate or helping behaviour (for example) will never be an entirely simple affair, even when one situation seems to be highly similar to situations one has previously experienced. Were the comments I wrote on the last paper I graded today appropriately critical, or were they unhelpful, because in grading the last it was situationally more salient to me that I had spent the entire day reading badly written papers? Usually one moves to assist someone who has stumbled into an obstacle. But what if the person is blind? Could she be learning her route from her bus stop to her door-step? Then should one intervene? Usually one offers a hand to an older person who has lost his or her footing. Yet Sir Arthur Conan Doyle relates the following tale of an interaction with his friend George Meredith: out walking in the woods with the elderly writer, a recent victim of a stroke, his companion fell behind him on the trail by several yards. When Doyle heard his friend trip over a tree root behind him, he did not retrace his steps to offer his assistance; indeed, he did not even turn around or interrupt the flow of conversation,

${ }^{50}$ Twain (1996), 24. The point is that Huck makes an immediate, unconscious inference from the sight of the lamplight to the possible existence of the suffering of others. A number of scholars have claimed that Aristotle construes the 'situational sensitivity' of the phronimos as a form of trained practical perception. Wiggins (1980), 232-233 describes this perceptual appreciation of Aristotle's moral agent this way: "A man usually asks himself "What shall I do?"... in response to a particular context. This will make particular and contingent demands on his moral or practical perception, but the relevant features of the situation may not all jump to the eye. To see what they are, to prompt the imagination to play upon the question and let it activate in reflection and thoughtexperiment whatever concerns and passions it should activate, may require a high order of situational appreciation, or, as Aristotle would say, perception (aisthêsis).' On ethical perception in Aristotle see also Shiner (1979) and Woods (1986). 
because he was acutely sensitive to his friend's sense of dignity and he did not want to draw attention to Meredith's infirmity. ${ }^{51}$

While it seems obviously correct therefore that situational variables can and do influence behaviour in the moral domain, it seems equally obvious that it is constitutive of virtue as it has been conceived in the virtue ethical tradition that these effects can be countered by the experience of a conscientious virtuous moral agent. Unfortunately, in the only remarks where Doris seems even to tangentially address the possibility of the acquisition of such experience, so familiar to common human sense, he seems to dismiss its cultivation as either impossible or improbable. ${ }^{52}$ In the course of responding to a worry about the 'ecological validity' of the situationist experiments Doris says this:

Seemingly insubstantial situational factors like mood, time pressures, and the presence of others have extraordinary effects generally. We can explain why the 'disconcerting potency' of small factors jumps out at us in experiments, as opposed to life, in this way: Given how counterintuitive it is to suppose that such factors powerfully influence behavior, it is no surprise that people typically pay them little attention, and even in the unlikely event that people developed situationist suspicions in the ordinary course of things, it would be difficult for them to engage in the systematic observation required to put such suspicions to the test. Conversely, this is just what experimental observation is designed to do; it's not that the experimentally identified phenomena are not present in natural contexts, but that they are not as readily there adduced. ${ }^{53}$

What Doris seems to be suggesting here is that the morally relevant factors of a situation are typically unobtrusive, because they are the product of unforeseeable moral luck. For that is why, presumably, Doris characterizes as 'unlikely' the attempt to develop 'situationist suspicions' to counteract such effects: one cannot develop a disposition to counteract the unconscious and unforeseeable effects of chance encounters with found dimes and subtle time pressures, if the effects of such situational variables are in fact unconscious and unforeseeable.

${ }^{51}$ Doyle (1924), 244. Doyle himself remarks on the complexity of the deliberation the situation called for: 'He was a fiercely proud old man, and my instincts told me that his humiliation in being helped up would be far greater than any relief I could give him. It was certainly a nice point to decide'.

${ }^{52}$ Doris also has a number of things to say about the moral education of the young (121-127). That topic lies beyond the scope of this paper. I am assuming however that the possibility of moral education and moral experience, while related, are distinct topics.

${ }^{53}$ Doris (2002), 36. The problem of 'ecological validity' of the situationist experiments concerns the question, to what extent do the situationist experiments reflect people's behavior in natural contexts? 
However, Doris is not entitled to claim, on the grounds that unobserved situational factors may have 'extraordinary effects', that such factors are unobservable, or that the situational variables that may influence a moral agent's behaviour are typically inscrutable to 'systematic observation.' The inference is illicit, and the suggestion is implausible. If Jane finds herself eating a large carton of popcorn at the movies when she had resolved the week before to go on a diet, chances are it is not because she has failed to develop the appropriate situationist suspicion that a clever social scientist is flashing subliminal images of buttery kernels on the screen; familiarly enough, it is much more likely that Jane's dietary downfall is due to her failure to plan accordingly (e.g. by eating beforehand, or by bringing only enough money for the show) in the light of her self-knowledge that she is helpless around movie popcorn. ${ }^{54}$

Now it is precisely the cultivation of such self-knowledge that Aristotle says characterizes the agent who is learning to become virtuous:

${ }^{54}$ In his 'Skepticism about persons' (2009) Doris argues that a number of psychological experiments (including those involving subliminal images or messages, 65) demonstrate that most of us get through our daily lives not on the basis of conscious intentions and deliberate choices but by mental processes caused by environmental stimuli that lie outside our conscious awareness. He argues that it follows that there is no such thing as a person, at least on the conception of a person which locates the distinctively human capacity for moral action in behavior regulated by reflective, self-conscious mentation, 60. Aimed at an Aristotelian conception of virtue ethics the view would deny that the phronimos exists on the grounds that the moral deliberation distinctive of such a moral agent does not exist. However, quite apart from the dubious suggestion that our actions are generally driven by such unconscious stimuli, this argument ignores the fact that Aristotle denies that the phronimos must always consciously deliberate when he acts. In fact Aristotle remarks that in many circumstances this is not the case: 'As for the premises in a practical argument, they are of two kinds---because of the good and because of the possible. And just as when we ask dialectical questions, so in this case also reasoning does not examine the second of these premises if it is obvious. For example, if walking is good for a man, reasoning does not waste time on the fact he is a man. Hence whatever we do without calculation we do quickly', De Motu 701a23-9. In Aristotle's view, many virtuous actions are instantaneous and hence involve instantaneous deliberation and decision. This is why the person who is unperturbed in a sudden alarm in war is more courageous than someone who stands firm because he knows the danger in advance. 'For what [the former] does is more the result of his state of character, since it is less the outcome of preparation. If an action is foreseen, we might decide to do it also by reason and rational calculation, but instantaneous action expresses our state of character' (NE 1117a16-22). Thus the courageous person may just see what he must do now and decide upon this without conscious deliberation or calculation. It seems clear that such remarks may be easily extended to the other virtues of character (e.g. those who are moderate around food and drink will not waste time deliberating whether to stick to their healthy regimen when dining out or grocery shopping). 
Excellence [i.e. virtue] of character...is effective at hitting upon the intermediate in affections [i.e., desires and emotions] and in actions. This is why being excellent is also something difficult to achieve. For in any context getting hold of the intermediate is difficult... whereas getting angry, or giving money away, or spending it are things anyone can do, and easy, doing them to the person one should, to the extent one should, when one should, for the reason one should and in the manner one should - this is no longer for anyone, nor is it something easy, which explains why getting things right is a rare thing, a proper object of praise, and something fine. Hence the person who is aiming at the intermediate should first move away from the more opposed extreme, following Calypso's advice:

That spray and surging breaker there- -keep your ship well clear of that.

For to arrive at one of the two extremes is more erroneous, to arrive at the other, less; so, since it is hard to hit upon the intermediate with extreme accuracy, one should take to the oars and sail that way, as they say, grasping what is least bad of what is available, and this will be most easily done in the way we say. ${ }^{55}$

In this text Aristotle is not suggesting that there is a mean response, or 'moderate' behavioural and emotional reaction to every situation that one must work one's way towards by avoiding the extremes. The doctrine of the mean does not entail, with respect to the appropriate expression of anger, for example, that if your neighbor is trivially rude to you on Tuesday and deliberately runs over your cat on Thursday that you must respond in a moderately angry way on both occasions. Aristotle is suggesting advice to young adults about finding the correct behavioural and emotional responses that would express the virtuous response; but virtue is a mean disposition, it is not a disposition towards a mean. There would not, after all, be that much for us to work out if we always simply had to respond in the same way in situations potentially provocative of a particular emotion or kind of behaviour. Aristotle is talking rather about the difficult problem of finding the different 'right target' in different token situations. 'Hitting the mean' simply means acting in accordance with what practical reasoning and correct moral habituation indicates is the appropriate emotional and behavioural response to the particulars of a situation. Getting things right in this sense is obviously difficult because it requires grasping, in the first place, what the morally relevant particulars of a situation are.

In the text above, Aristotle is suggesting, quite reasonably, that there are a number of ways in which human beings can subject such particulars to 'systematic observation.' $\mathrm{He}$ is offering advice to someone who is still learning how to hit the mark; and he is ${ }^{55} N E$ II.9 1109a24-b1. 
reminding us of the fact that with respect to some goods anyway-especially bodily pleasures (1109b10)---one extreme is 'more erroneous' than another. He means, I suggest, both that it can harm us more than its contrary - too much pleasure can be more harmful than its deficiency---and that we have a natural human tendency more towards one extreme than its contrary. Thus 'staying clear of the surging breakers' means: know what kind of creature you are. If one takes such advice to heart, one will not, (for example) if one is a heterosexual male in the teaching profession, give world-transforming hugs to an adoring female student to congratulate her on some academic achievement. Here it is the normal life experience of human beings that usefully supplies the knowledge that situations of that particular sort are typically fraught with moral danger.

But in addition to knowing themselves in this generic sense, Aristotle insists that moral learners must also acquire knowledge of their own particular humanity:

And we should consider the things that we ourselves, too, are more readily drawn towards, for different people have different natural inclinations; and this is something we shall be able to recognize from the pleasure and the pain that things bring about in us. We should drag ourselves away in the contrary direction; for by pulling far away from error we shall arrive at the intermediate point, in the way people do when they are straightening out warped pieces of wood. ${ }^{56}$

Again, the point is not that by thus 'dragging ourselves' from the objects of our natural inclination, we shall arrive at some 'mean amount' of pleasure or anger. The mean is not an arithmetic mean, and moderato in omnibus is not a principle that Aristotle defends in his ethical system. ${ }^{57}$ What is being described rather is the diachronic process of learning to respond, emotionally and behaviourally, in the appropriate way, as a result of constant practice, in the light of one's recognition of one's own potential weaknesses: John has a tendency in social situations to run off at the mouth and make inappropriate remarks in a nervous attempt to be witty; but he may remind himself of that before the party, and resolve that he will ask people about themselves, instead of trying to make them laugh. ${ }^{58}$ Eventually, Aristotle's point is, he will not have to be so cautious. Though it will take much practice, eventually he will hit the right social note without much conscious effort.

\footnotetext{
${ }^{56} N E 1109 \mathrm{~b} 2-8$.

${ }^{57}$ Aristotle explains the sense in which the mean is not arithmetic at II.6 1106a20-b9.

${ }^{58}$ Aristotle thinks wit is a social virtue. Cp.NE IV.8.
} 
Another way in which virtue ethics may counter Doris' skepticism on the possibility of acquiring such moral experience is by pointing to the relationship between what Aristotle calls the 'external goods' and the virtues of character. Aristotle recognizes essentially three types of goods: the goods of the body (health, beauty, etc.), the goods of the soul (e.g. the psychic states that are the virtues and the activities that are their ends, viz., primary and secondary eudaimonia), and the external goods (a category which includes honour, money, friends, good birth, and the bodily and social pleasures). ${ }^{59}$ The external goods and the goods of the body are a result of luck. ('It is not possible to be eudaimôn without external goods, which luck controls', MM 1206b22-4; cp. NE 1153b1619: 'No activity is complete if it is impeded, and eudaimonia is something complete. Hence the eudaimôn person needs to have goods of the body and external goods added, and needs luck also, so that he will not be impeded in these ways'; cp. MM 1183b27-35.) The goods of the soul are not controlled by luck: 'The goods external to the soul come of themselves and by luck, whereas no one is just or temperate on account of luck', Pol. 1323b27-9). ${ }^{60}$

However, Aristotle makes a division between external goods: money, honour, and bodily and social pleasures are the sorts of things that human beings, as social animals, compete for; other external goods, given their nature (e.g. beauty, good birth) do not lend themselves to social competition. (Cp. 1168b15-19: 'Those who make self-love a matter of reproach ascribe it to those who award the biggest share in money, honours, and bodily pleasure to themselves. For these are the goods desired and eagerly pursued by the many on the assumption that they are the best; and hence they are also the goods that are competed for.' Cp. 1169a20-1.)

It follows that the virtues of character will be particularly concerned with having the appropriate feelings and desires (or appetites, epithumiai) with respect to the first

${ }^{59} N E$ 1098b12-16; cp. $M M$ 1184b1-6. 'Primary eudaimonia' for Aristotle is being continually active in the life of contemplation (i.e., doing philosophy). 'Secondary eudaimonia' is being practically active in a life that expresses the virtues of character and phronêsis.

${ }^{60}$ I cite the passage simply for the sake of its succinctness; it is hardly the only place in Aristotle's ethical system where he makes this point. Aristotle argues in detail in $N E$ that moral agents are responsible for the virtues or vices of character that they end up with. His argument that we become just, or courageous, or moderate by performing just or courageous or moderate actions unfolds in a complex fashion throughout $N E$ Books I-VI; but see especially his conclusion of his discussion of the voluntary III.5 1114a12ff; also II.2 1104a11-b3. 
category of externals. Indeed, it is for precisely this reason that Aristotle organizes the virtues and vices of character in the way that he does, and why he claims (1115a5) that we may feel reasonably confident that his list includes all the virtues and vices that there are. The virtues and vices of character are hexeis, or states; and states are what we have when we are well off or badly off with respect to our emotions and desires. If for example our emotion or appetite for revenge is too strong or too weak in relation to anger, we are badly off; if it is appropriate (or 'intermediate', as Aristotle puts it), we are well off. Since 'appetite's concern is with what is pleasant and what is painful' (1111b16-18), and since 'the emotions all involve pleasure and pain' (1105b21-3), and since the externals that are competed for are 'sources of pleasure' (1147b23-31), the general moral disposition of the phronimos to act and feel in accordance with what practical reason requires may be analyzed as the various virtues of character, i.e., as the various ways in which it is possible to respond appropriately to these kinds of externals. By the same token, the various vicious states of character may be defined in terms of the various ways it is possible for human beings to go wrong in the pursuit of these recognized objects of social competition.

Thus according to Aristotle, the virtue of courage is concerned with painful emotions of fear and the pleasant feelings of confidence in the face of danger. ${ }^{61}$ Moderation (or the virtue of 'temperance') is particularly concerned with the pleasures and pains of taste and touch (including especially, of course, the pleasures and pains involved in eating, drinking, and sex). ${ }^{62}$ Generosity and magnificence are concerned with wealth or money (on a smaller or larger scale, respectively). ${ }^{63}$ The virtue of magnanimity is concerned with honour. ${ }^{64}$ Mildness is concerned with the emotion of anger, a painful emotion that is in turn concerned with honour (the formal component of the emotion of anger Aristotle defines in terms of the belief that one has been insulted, and the desire to exact revenge) ${ }^{65}$ The

${ }^{61}$ II.3 1104b3-8; III.9 1117a29-b18.

${ }^{62}$ Cp. e.g. NE $1118 \mathrm{a} 23-\mathrm{b} 8$.

${ }^{63}$ IV.1-2 passim.

${ }^{64}$ IV.3 passim .

${ }^{65}$ IV.5 passim; cp. Rhet.1378a32. Aristotle defines the emotions 'hylomorphically': the material component of the definition brings in the somatic constituents of an emotion. In the case of anger, Aristotle thinks this is 'blood boiling around the heart' (DA I.1, 403a30-b1). Dow (2011) argues 
nameless virtue that is a mean between being ingratiating and being contentious is concerned with the pleasures and pains involved in social exchanges. ${ }^{66}$ The similarly nameless virtue that is a mean between boastfulness and self-deprecation is concerned with the emotions of confidence, envy, and jealousy, feelings that may cause us to have too high or low of an estimate of our own sense of honour or self-worth. ${ }^{67}$ The virtue of wittiness is concerned with what is socially amusing, the virtue of friendliness with the social pleasures other than amusements. ${ }^{68}$ The virtue of 'special justice' is concerned with avoiding pleonexia, or the desire for more and more of the external goods of competition without limit. ${ }^{69}$

The point is not merely that it is already well known what the morally relevant situational variables of human action and choice are; more importantly, the point is that we have little choice but to constantly acquire moral experience as we respond to these particular features of our moral landscape. Because we are social creatures who are in constant competition for these goods, we have no choice but to acquire and cultivate experience (including and especially emotional experience) as a result of their pursuit. If Aristotle, or the virtue ethical tradition in general is right, it is what we learn, for better or worse, with respect to these particular situational variables above all others that will determine whether we will fare well or badly in our pursuit of happiness in general. ${ }^{70}$

that in Aristotle's view, to experience an emotion is precisely to experience pleasure or pain (or both), in a way that is intentional and representational.

${ }^{66}$ IV.6 passim .

${ }^{67}$ IV.7 passim.

${ }^{68}$ IV.8 passim .

${ }^{69} 1129 \mathrm{~b} 1-4$.

${ }^{70}$ Perhaps it is worth pointing out that this last statement does not entail that Aristotle (or again, the virtue ethical tradition generally) endorses the view that 'happiness' is a good state of well-being (e.g. in the sense of a sense of security) that one acquires as a result of virtuous action. Practical virtuous activity is eudaimonia (or secondary eudaimonia) according to Aristotle: though the eudaimôn person will experience much pleasure and contentment in his or her life, eudaimonia is not pleasure or contentment; it is rather excellence in practical or contemplative activity, and such activity is choiceworthy both for its own sake and for the sake of its pleasant consequences, including (in the case of secondary eudaimonia) the opportunities for primary eudaimonia it affords. On this point see especially NE X.7, 1177b2-18 and Pol. 1334a11-40. 
The foregoing argument may seem to invite the objection that in the Darley and Batson study, the relevant situational variable that seemed to be causally explanatory and predictive of the seminarian's behaviour was not an instance of an 'external good'; it was simply the temporal factor of whether or not the subjects believed that they were hurried or not. However, the point is not-once again - that all possible morally relevant situational variables must be on Aristotle's list of external goods. The point is rather that the external goods Aristotle identifies are morally relevant because they can and typically do form the particulars upon which the particular form of ethical learning which Aristotle calls moral habituation (êthikê) is performed. ${ }^{71}$ But if that is so, then even so 'unobtrusive' a situational variable as hurry may form the basis of ethical learning: a fact that is evident from the expressions of agent regret on the part of some of the seminarians, whose capacity for 'retrospective' deliberation, and hence moral learning, was apparently not in every case merely prompted by the post-experiment interview. ${ }^{72}$ Since, as I have suggested above, Aristotle conceives of the general moral disposition of the phronimos as a capacity to act and feel under the guidance of practical reason, it is open to the virtue theorist to admit indefinitely many types of situational variables as new domains of moral attention. ${ }^{73}$ It would seem that in the face of such evidence, if Doris insists that the situational variables that typically influence human moral behaviour must be incapable of 'systematic

${ }^{71}$ Cp. NE 1103a17-20: 'Excellence of character [êthikê] results from habit [tou ethous]—which is in fact the source of the name, being a slight variation of that for 'habit'.

72 Darley and Batson (1973), 50.

${ }^{73}$ Kamtekar (2004), 481 makes a similar suggestion. Alternatively, though perhaps less plausibly, the virtue ethicist could attempt to subsume acting in a mean with respect to time under one of the other recognized virtues. A promising candidate in this regard may be the Aristotelian virtue of magnanimity, the excellence of the 'great-souled' (megalopsuchos) person. This virtue involves both being and truly thinking oneself worthy of great things; it therefore has to do with honour, the 'greatest of the external goods.' (1123b15-26). The great-souled person is not impressed by very much (1125a3), and hence does not 'risk himself for small things, because there are few things he values' (1124b5-6); 'slow movement seems to be characteristic of the great-souled person.....and steady speech; for the person who takes few things seriously is not the sort to hurry, nor is someone who is impressed by nothing the sort to be tense.' It is difficult to imagine the megalopsuches bustling off to assist the confederates in Darley and Batson with his attention utterly absorbed by the prospect of giving a 3-5 minute talk to complete strangers on the subject of vocational opportunities in the ministry. 
observation', then he must explain why it is appropriate to assess such behaviour as morally blameworthy or praiseworthy in the first place. ${ }^{74}$

A final objection that may be made to Doris' interpretation of the seminarian experiment is in a sense dialectically prior to those I have addressed so far. If I have saved it for last, it is in the hope that it may be more readily understood in the light of the foregoing remarks on the nature of virtue and practical wisdom as it has been conceived in the virtue ethical tradition. According to Doris, it is only on the assumption that compassion is a 'robust trait' that the seminarian experiment will show that the conception of this virtue is empirically inadequate. However, as other scholars have complained, Aristotle does not conceive of compassion or any other virtue as a robust trait in Doris' sense. ${ }^{75}$ It is Doris who conceives of the virtues of character on the model of a chemical disposition: drop the compassionate agent in a compassion-eliciting situation and she will melt with compassion. Place the courageous agent in courage-eliciting circumstances and he will seethe reliably with courage, exhibiting 'trait-relevant' behaviour that is 'cross-situationally consistent.' As these critics have pointed out, the virtue ethicist conceives of a virtue as a rational disposition. A virtue is a disposition to act and feel in an appropriate way as a result of and in response to rational considerations about the good in particular circumstances. The acquisition of virtue is a difficult moral achievement because it involves the complex and interdependent development of both the intellectual and emotional capacities of a human being.

We may fill out this objection by noting that in Aristotle's system, the picture of moral knowledge that results from the full development of these capacities may be said to have two major components. The first component explains our grasp of ethical universals such as the properties of justice or courage or moderation, as well as our grasp of the first principle of ethics, eudaimonia. ${ }^{76}$ The second component explains how we can come to

${ }^{74}$ Doris does address this last point at least tangentially in his chapter 7, 128-153 on situationism and responsibility. Rather frustratingly however he here describes his own account of responsibility as 'breezy, glib, and quasi-clinical'.

${ }^{75}$ Kamtekar (2004), 474; Annas (2005); Leunissen (2017).

${ }^{76}$ The details of Aristotle's system of course should not detain us here; but it may be of interest to the general reader that this first component of moral knowledge includes a dialectical (i.e. philosophically defensible) understanding of what eudaimonia amounts to. This requirement is another factor that, according to Aristotle, contributes to the rarity of the acquisition of full-blown 
know how to apply our grasp of such morally relevant universals in particular situations---where this latter kind of knowledge crucially involves knowing both how to act and how to respond emotionally to one's circumstances.

As we have seen however, Aristotle denies that this second component of ethical knowledge admits of any kind of precise specification or exactness that would lend itself to the predictability of robust traits in the situationist's sense. Thus in one of the most famous passages of the Nicomachean Ethics, Aristotle says that with respect to the nature of ethical knowledge,

Our account would be adequate, if we achieved a degree of precision appropriate to the underlying material; for precision must not be sought to the same degree in all accounts of things, any more than it is by craftsmen in the things they are producing. Fine things and just things, which are what political expertise inquires about, involve great variation and irregularity, so that they come to seem fine and just by convention alone, and not by nature. Something like this lack of regularity is found also in good things, because of the fact that they turn out to be a source of damage to many people: some in fact have perished because of wealth, others because of courage. (I.3 1094b13-20; cp. I.7 1098a22ff.)

Upon first blush it may seem that the 'irregularity' with respect to courage that Aristotle is pointing to here involves the possibility that the virtue of courage may harm its possessor. However, that is not what Aristotle means. A real virtue always benefits its possessor. What Aristotle is alluding to here rather is the 'natural virtue' of couragemoral disposition that is precisely what the situationist would describe as a robust trait of character. ${ }^{77}$ The naturally courageous do reliably exhibit 'courage-relevant' stereotypical behaviour in 'courage-eliciting conditions.' But that is why, as Aristotle remarks, such bluff fellows so often end up stupidly dead: it is because their natural disposition to feel confident (e.g.) in fearful circumstances is not appropriately integrated with either an intellectual understanding of the human end (the good, eudaimonia), nor with the deliberative excellence of practical reason. (In fact, the naturally brave lack the latter altogether. $)^{78}$

moral excellence (besides its general difficulty of attainment, and apart from cruelties of the natural lottery, e.g., whether one has had good parents or not).

${ }^{77}$ Cp. NE 1144b5-22, 1116b24-1117a1.

78 'Natural dispositions belong to children and animals as well: but without intelligence to accompany them, they are evidently harmful...just as a powerful body when moving without sight 
It is therefore precisely because the virtues are not robust traits of character that the deliverances of practical reason, even when it is operating in its fullest capacity, will issue in decisions in particular circumstances that are never 'cross-situationally' consistent in the situationist's sense. Thus the passage above continues:

We must be content then, when talking about things of this sort [i.e. fine and just things], and starting from them, to show what is true about them roughly and in outline, and when talking about things that are for the most part, and starting from these, to reach conclusions too of the same sort. It is in this same way, then, that one must also receive each sort of account: for it is the mark of an educated person to look for precision in each kind of inquiry just to the extent that the nature of the subject allows it; it looks like the same kind of mistake to accept a merely persuasive account from a mathematician and to demand demonstrations from an expert in oratory. (1094b20-28)

In this text Aristotle is clear that it is the nature of moral knowledge itself, and not just how we describe it or talk about it that is ultimately responsible for its being true only 'for the most part.' What is ultimately responsible in turn for moral knowledge being of this nature is frequently reiterated in $N E$. The following passage, which back-references the text above, is typical:

Let it be agreed that everything one says about practical undertakings has to be said, not with precision, but in rough outline, just as we also said at the beginning that the sorts of account we demand must be determined by the subject matter: things in the sphere of action and things that bring advantage have nothing stable about them, any more than things that bring health. But if what one says universally is like this, what one says about particulars is even more lacking in precision; for it does not fall under any expertise or under any set of rules - the agents themselves have to consider the circumstances relating to the occasion, just as happens in the case of medicine, too, and of navigation. (II.1104a1-11).

What Aristotle means here is that it is not only the law-like relations between the universals with which the first component of ethical knowledge is concerned that will be probabilistic to a certain extent. There will be even less exactness in ethical knowledge at the level of the agent's grasp of the morally relevant particulars in any given situation. ${ }^{79}$ It is highly significant that Aristotle compares this level of ethical knowledge to the art of

to guide it will fall with powerful impact because of its sightlessness, so it is in this case too' (1144b9-12).

${ }^{79}$ For a useful treatment of Aristotle's account of ethics as an inexact science, see Irwin (2000). Irwin denies (rightly in my view) that the role of particulars in Aristotle's system entails a commitment to moral particularism, i.e. the thesis that perceptual judgments about particular situations are normatively prior to universal rules. 
medicine. Aristotle thinks that the truths of physics, biology, psychology, and the other natural sciences also hold 'only for the most part. ${ }^{80}$ But if he thinks these disciplines are probabilistic to some degree, he thinks medicine is downright stochastic - and he says so in many interesting comments that he makes, in the Ethics and elsewhere, about the art of medicine. ${ }^{81}$ Experience teaches that a draught of some drug has been beneficial in the past for certain individuals suffering from fever. But it takes art to grasp the universal under which these individuals fall (e.g. phlegmatic, bilious). ${ }^{82}$ It requires even greater skill to grasp how to apply this knowledge in particular cases. For the draught is not always curative of patients falling under such types; it depends. What is the cause of the fever? How long has the patient been suffering from it? How old is the patient? Is he otherwise healthy or is he moribund? What sex is the patient? If Aristotle and the virtue ethical tradition that is inspired by him take ethics to be comparable to medicine in this respect, the virtues of character cannot be robust traits.

The stochastic nature of ethics and ethical knowledge is one of the most commented on features of Aristotle's moral epistemology. Doris passes over it in complete silence, despite the fact that he clearly regards Aristotle as the highest-value target in his refutational sights.

\section{$\S 3.2$ Milgram Reconsidered}

According to Doris, the Milgram pain studies are powerful evidence for situationism because

[the] experiments show how apparently non-coercive situational factors may induce destructive behavior despite the apparent presence of contrary evaluative and dispositional

${ }^{80}$ Metap.1027a20-1; cp. Ph. 197a19-20.

${ }^{81} \mathrm{Cp} . N E 1121 \mathrm{~b} 1 \mathrm{ff}:$ 'And in the case of exact and self-contained sciences there is no deliberation, e.g. about the letters of the alphabet (for we have no doubt how they should be written); but the things that are brought about by our own efforts, but not always in the same way, are the things about which we deliberate, e.g. questions of medical treatment or of money-making [...]. Deliberation is concerned with things that happen in a certain way for the most part, but in which the event is obscure, and with things in which it is indeterminate.' Aristotle is very interested in comparing the epistemological status of ethics, medicine, and the law in particular. Cp. NE 1180b728; 1181a15-b11; 1137b9ff; Resp. 480b21-30; Sens. 436a14-21; Pol. 1282a1-4; Top. I.3.

${ }^{82}$ Metap. 981a1-12. 
structures. Furthermore, personality research has failed to find a convincing explanation of the Milgram results that references individual differences. Accordingly, Milgram gives us reason to doubt the robustness of dispositions implicated in compassion-relevant moral behavior [...]. ${ }^{83}$

Thus Doris interprets the behaviour of the subjects in the Milgram experiments as conflicted---'the most striking feature of the demonstration is not blind obedience but conflicted obedience'- but he takes it that the presence of conflict in the subjects can only provide further support for a situationist reading of the experimental results. ${ }^{84}$ The reason advanced for this claim is that the presence of conflict only underscores the fact that any evaluative dispositions that may have been responsible for the subject's conflicted feelings--the presence of their 'contrary evaluative and dispositional structures'---were 'swamped' by the situational factors of the experiment. It was therefore the situational variables of their circumstances, and not the presence of individual differences, that were causally efficacious and explanatory of whether a subject was obedient or not, and when, in the Milgram experiment. Doris concludes that the existence of the subjects' evaluative dispositional structures does not warrant the attribution to the subjects of any robust trait of character (e.g. of compassion). Though the (surmised) presence of certain 'evaluative structures' was evidently strong enough to cause emotional conflict, the presence of the trait of compassion cannot be inferred from the mere presence of conflicted feelings, because while almost all subjects felt conflicted, the majority were (to some degree, at least) obedient.

In the course of defending his interpretation of the experiment, Doris reiterates in a number of different ways that it is the attribution of a virtue of character that the Milgram study shows to be empirically unjustified. Thus he notes that different manipulations of the experiment produced different levels of obedience, 'further proving the point' that it is the situational variation and not individual characterological differences that caused the subjects' behaviour. ${ }^{85}$ ('Or is it to be supposed that 39 virtuous subjects and one vicious subject were assigned to the 3 percent obedient 'subject chooses shock level condition, while 37 vicious subjects and three virtuous subjects were assigned to the 93 percent

\footnotetext{
${ }^{83}$ Doris (2002), 39.

${ }^{84}$ Ibid. 39.

${ }^{85}$ Ibid. 46.
} 
obedient 'peer administers shocks' condition?'). ${ }^{86}$ Again, remarking on one permutation of the study in which $73 \%$ of teenagers were obedient, and on another where teenagers obediently inflicted pain on themselves, Doris rebuts the suggestion that the subjects' age is relevant by noting that while one may expect that with increasing age subjects would exhibit increasing autonomy ('or to wax Aristotelian, fuller character development'), the experimental results do not show this. ${ }^{87}$ And to the objection that no longitudinal personality studies were conducted on the Milgram subjects, Doris counters that there is as little reason to suppose that such studies would reveal that disobedient subjects could be counted to exhibit 'Socratic self-mastery' in other situations, as there is to expect that obedient subjects would habitually inflict severe shocks to their family and friends. ${ }^{88}$

I am inclined to agree with Doris that the results of the Milgram study give us little reason to expect that disobedient subjects might prove to be either 'robustly' compassionate or resistant to authority. I am also inclined to agree that the emotional conflict of the subjects gives us no reason to infer that the subjects were possessed of a 'robust' trait of compassion. But that is because I am further inclined to agree with Doris that the best explanation of the widespread obedience in the Milgram study is that the subjects faced a 'justification problem':

The subject is first asked to do something seemingly rather trivial, administering a very slight shock, followed by only a relatively slight increase in voltage each time. If a subject eventually balks, he is faced with a 'justification problem': why is it wrong to administer this level of shock and not the shocks previously administered? Such justification was available at only one point in the experiment, when the victim withdrew his implied consent...in fact, for most permutations of the experiment, this was the single point at which most defiance occurred. ${ }^{89}$

Where I part company with Doris is in finding any support in this suggestion for a situationist reading of Milgram. The choice, as Doris sees it, in explaining the Milgram results comes down to the person or the situation. But as we have just seen, Doris equates 'the person' with individual characterological differences, i.e. the virtues of character.

${ }^{86}$ Ibid. 46.

${ }^{87}$ Ibid. 47.

${ }^{88}$ Ibid. 48-49.

${ }^{89}$ Ibid. 50. For accounts of the 'justification problem' interpretation of Milgram see Gilbert (1981) and Ross (1988). 
However, as we argued in the previous section, Doris fails to see that in the virtue ethical tradition, the virtues of character are incapable of operating in isolation from the deliberative (and hence intellectual) virtue of practical wisdom. It is therefore open to the virtue ethicist to interpret the justification problem as a failure, not in character excellence, but in deliberative capacity. We can agree that the Milgram scenario is not 'diagnostic' for the moral characters of the few subjects who were disobedient. But it is not implausible to suggest that the experiment could be diagnostic for at least various degrees of deliberative excellence. All the subjects faced a novel deliberative problem. Most were emotionally conflicted, and so presumably had in place (as Doris puts it) 'evaluative dispositions' contrary to willfully and pointlessly inflicting harm on their fellow human beings. What seems to have happened is that many subjects quickly found it problematic to fully integrate their standing evaluative attitudes and their capacity to deliberate in this particular situation. Those who solved the 'justification problem' the soonest may therefore be seen as exhibiting, not a robust trait of compassion or resistance to authority, but a degree of skill in integrating their values and their practical reasoning to a degree that others lacked.

It is possible that Doris would complain that this reading of the experiment simply relocates problematic attributions of robust traits to the intellectual column of the virtues recognized in the virtue ethical tradition. ${ }^{90}$ I believe the appropriate response is to challenge Doris to (a) provide an account of practical reasoning that makes it out to be a 'robust trait' in the situationist's sense; (b) establish that virtue ethicists and/or people in general conceive of deliberative excellence as a robust trait; and (c) conduct longitudinal (or at

${ }^{90}$ This is precisely the objection that Doris raises, n.22, 214, to Bok (1996). She argues that the Milgram subjects were not akratic (deciding to obey the confederate rather than their own beliefs about how best to act), but were rather 'paralyzed' by their dilemma so that they failed to make any decision at all. Because I am endorsing the justification problem solution (or my interpretation of it above), I believe my account of the subjects' plight is different from Bok's. I see the subjects as neither paralyzed nor indecisive, nor as akratic, but as repeatedly trying to deliberate at each stage of the experiment and being unable to make sense of their own deliberation. Bok is said by Doris to 'relocate' the situationist difficulty to the attribution of the 'robust trait' of [having] the moral 'fiber' that is needed for subjecting a difficult problem to 'appropriate reflective scrutiny.' I believe my own interpretation above eludes this charge, for the reasons given. 
least follow-up) studies on subjects in Milgram-type studies that establish that these experiments are not diagnostic for deliberative skill. ${ }^{91}$

\section{$\S 3.3$ Mood Effects and Heroic Virtue}

Doris argues that what is especially significant about the Isen and Levin study is that it highlights the disproportionality that may exist between an agent's behaviour and his or her situation. Unlike the Milgram experiment, the setting of this study is utterly mundane. Moreover, it tests for moral behaviour that is utterly mundane as well: the study is not concerned with 'behaviour in extremis, but behaviour in situations that are rather less than extreme. ${ }^{, 92}$ Subjects failed to behave compassionately, when it would have been very easy to do so. The fact that it was the presence of a mere dime that induced compassionate behaviour is powerful evidence for situationism, because

If dispositional structures were so typically robust as familiar conceptions of character and personality lead one to believe, insubstantial factors would not so frequently have such impressive effects. ${ }^{93}$

Now it seems clear that since $96 \%$ of non-finders in the study failed to help, the best explanation of the behaviour of those that did help was that they lucked into the dimes. The question is, what does this conclusion entail for virtue ethics? Doris considers the fact that one person did help the confederate, despite not finding a dime. Perhaps then the study shows that virtue is 'rare and difficult to achieve'? Doris' response is that

This is not a case requiring heroic commitment or sacrifice, but rather minimally decent "prosocial behavior." [...] I am not establishing a heroic standard for good character and arguing from the rarity of this standard [...] to a general skepticism about characterological moral psychology. Rather, there are problems for standards of character that are well short of heroic. ${ }^{94}$

${ }^{91}$ If Doris (2009) is any indication, rather than address these issues he has elected to argue that no one is a deliberator in Aristotle's sense. Cp. n.54, 25.

${ }^{92}$ Doris (2004), 28.

${ }^{93}$ Ibid. 28.

${ }^{94}$ Ibid. 31-32. 
However, despite his protestations to the contrary, it would appear that Doris does mean to uphold a heroic standard for good character. The circumstances of the study justify the claim that heroic sacrifice was not required on the particular occasion in order for the subjects to have behaved compassionately. Nevertheless, Doris' construal of the virtues of character as robust traits clearly does require a heroic standard of virtue in terms of the frequency or probability of the expectation of helping. For Doris takes the assumption that virtues are robust traits to entail both that the compassionate person will execute compassionate behaviour unfailingly whenever behaviour of that sort is required by his or her circumstances, and that the agent will always refrain from performing actions that are insensitive, no matter what distractions may be present and regardless of any inducements to do otherwise. ${ }^{95}$ Since the virtue ethicist does not take the virtues to be robust traits, she may simply deny that the virtuous person is 'diachronically heroic' in the sense Doris requires.

The virtue theorist can, in other words, allow that a virtuous person may commit the occasional error of omission. The virtuous person will never, in the full knowledge of what virtue requires, act against his virtuous disposition. But he may occasionally fail to be fully aware of the morally relevant particulars of his situation prior to acting. Aristotle would seem to agree:

It is not the person who deviates a little from the right path who is censured...rather it is the person who deviates significantly, for there is no missing him. (NE II.9 1109b19-21) $)^{96}$

${ }^{95}$ Ibid. 17-18.

${ }^{96}$ I believe it is clear from the context that the 'extent' of the error to which Aristotle refers here includes the frequency, not just the seriousness, (and perhaps not even the seriousness) of error. Cp. 1126a35-b5: 'It is not the person who deviates a little who is censured, whether he does so in the direction of excess or of deficiency; since sometimes we praise those deficient in anger and call them mild, and we call those who get angry manly, on the basis that they are capable of taking charge. So as to how far and in what way a person must deviate to be worthy of censure, it is not easy to define it in words; for the judgement of such things lies in our perception of the particular circumstances.' In both texts, Aristotle is considering what kinds of repeated errors of a certain kind must be committed before one becomes a person of a certain (blameworthy) type. Curzer (2005) argues persuasively that in fact it was never Aristotle's project to portray the phronimos as an idealized but unrealizable type in his ethical works. On the contrary, the person of practical wisdom may behave in a manner that is less than morally perfect due to a number of reasons (including minor flaws or tendencies within his own character); nevertheless such a person's character is good enough to count as virtuous. 
What then is the diachronic standard of virtuous behaviour? How far and how often must one go wrong before we withdraw the attribution of virtue? Aristotle suggests that given the nature of ethical knowledge, this may only be determined on a case by case basis:

But as to how far and to what extent one has to deviate to be worthy of censure, it is not easy to fix in words, any more than anything else that belongs to the sphere of perception; for such things depend on the particular circumstances, and the judgment of them lies in our perception. (1109b2225)

What Aristotle says elsewhere about diachronic standards of virtue fills out the sense of this text. Of all the different kinds of activities that human beings can engage in, virtuous activity is that in which a human being is most able to be continuously active. ${ }^{97}$ As long as the necessary external goods are in place which facilitate such action (at least some money, at least some friends, etc.), one can be even more continuously active in virtue than one can be in the special sciences (e.g. mathematics):

For in no aspect of what human beings do is there such stability as there is in activities in accordance with excellence: they seem to be more firm-rooted even than the various kinds of knowledge we possess; and of these very kinds of knowledge the most honourable are more firm-rooted because of the fact that those who are blessed spend their lives in them more than anything, and most continuously, for this is likely to be why forgetfulness does not occur in relation to them. (1100b13$18)$.

The sense is that whereas (e.g.) mathematical knowledge may be present at times when its activation is not called for, the occasions on which virtue will be needed in the contingencies of life will be much more frequent; since this is so, while a person may experience some deterioration in his capacity to exercise his scientific knowledge, he will never suffer such forgetfulness in the case of the exercise of the excellences of character and practical reason.

Since virtuous activity is thus ranked above all others in terms of its possibilities for continuity, and since activity in accordance with virtue is the most choiceworthy kind of activity that human beings can engage in, it will follow that the virtuous agent will want

${ }^{97}$ Aristotle thinks one may be even more continuously active in theoretical contemplation than in activities in accordance with the practical virtues. (See NE X 6-8 for the arguments for this claim.) But Aristotle's distinction between primary and secondary eudaimonia does not affect the present point, since he thinks the intellectual virtues of nous and sophia are activated in primary eudaimonia. 
to perform virtuous actions whenever it is possible and appropriate for him to do so. In fact, given his interesting theory of the role of pleasure in moral habituation, Aristotle is in a position to claim that the properly morally habituated person has a built-in feedback mechanism that will enable him to be as continuously active in virtue as it is possible for a human being to be:

[An] activity's own pleasure contributes to increasing the activity. It is those who are active and take pleasure in it that are more discriminating and precise in relation to a given subject, e.g. those who delight in geometry are the ones that become expert in geometry, and are always more able to see things, and similarly the lover of music, or building, or whatever it may be - each gets better at his own task through taking pleasure in it; and the pleasures contribute to the increase. (1175a30$35)$.

Thus the more an agent has experienced the pleasures of virtuous action, the more morally perceptive he will become; and the more morally perceptive he becomes, the more continuously active in virtue he will be, as his awareness of the occasions for virtuous activity deepens and expands. ${ }^{98}$ But it does not follow for Aristotle-nor should it be thought to be a commitment of any virtue theorist - that the accumulation of such experience will eventuate in a god-like omniscience of the possibilities for virtuous action in play at every waking moment of the virtuous person's life. Aristotle says only that the virtuous agent 'will always, or most of all people, do and reflect on what is in accordance with excellence.'(1100b20-21). He explicitly distinguishes merely human excellence from 'superhuman excellence, i.e., one of a heroic or even divine sort.' (NE VII.1 1145a20-30). ${ }^{99}$

98 This explains why it is so difficult for the akratic person to become virtuous: his pleasure in virtuous action is discontinuous. According to Aristotle, most of us are akratic to some degree or other about various domains of action. Most of us who are akratic are uncontrolled with respect to bodily pleasures. ('Now for most people the things that are pleasant are in conflict, because they [i.e., their pleasures] are not such [i.e. pleasant] by nature.' (1099a12-14). Whereas the vicious person then is incurable, insofar as he may be compared to someone with a disease like dropsy or consumption, the akratic is curable, since 'lack of self-control resembles [a sort of disease] involving seizures; for the one is a continuous, the other a non-continuous way of being as one shouldn't be.' (1150b32-35). But he will only be 'curable' with great difficulty.

${ }^{99}$ This opening paragraph of $N E$ VII.1 actually contains more evidence against Doris' reading of Aristotle than I have indicated above. Aristotle explicitly recognizes six states of character in this text (divine excellence, human virtue, self-control or enkrateia, lack of self-control or akrasia, vice, and brutishness). It is clear from what he says here, as well as his entire discussion of akrasia and self-control in Book VII, that he regards the akratic and the enkratic as types of person. The akratic person however is partially defined in terms of the inconsistency of his behaviour. Akrasia as a trait of character therefore cannot be conceived as a robust trait in Doris' sense. On those occasions when Doris discusses akrasia, he seems to suppose that it is a kind of action (an occasion of acting 
What sets us apart from the divine is precisely our limited capacity for continuous action: human beings get tired; god does not. ${ }^{100}$ Robust dispositions however are neither human (because they are diachronically heroic) nor divine (because they are stupid). ${ }^{101}$ Insofar as the Isen and Levin study is taken to prove the empirical inadequacy of the attribution of robust traits, it would therefore seem to hold little significance for virtue ethics.

\section{\$4.0: Doris on the Fragmentation of Character}

I turn now to consider the positive thesis of Lack of Character. This is the recommendation that moral theorists, personality psychologists, and people in general abandon the practice of 'global' attributions of character in favor of the attribution of 'local traits.' It will be recalled that 'globalism' is Doris' term for the (allegedly) virtue ethical conception of personality and moral character as an evaluatively integrated association of robust traits. Doris takes the results of the situationist experimental record to show that the globalist conception of personality and character is incapable of accounting for the variability and inconsistency of human behaviour. If our personalities and moral characters were typically structured as evaluatively integrated sets of robust traits, we would expect to observe substantial consistency in morally relevant behaviour. Since the situationist experiments do not support this expectation, Doris contends that moral character and personality in general should be conceived as fragmented, i.e., as manifesting a looser structure of evaluatively disintegrated situation-specific local traits. ${ }^{102}$

against one's decision), rather than a trait of character resulting in akratic action. (Cp. 134). I do not pursue the point however because Doris' discussion of responsibility and akrasia lies beyond the scope of this paper.

100 'Continuous activity, after all, is impossible for any human capacity', NE X.4 1175a4-5.

${ }^{101}$ By 'divine' here I mean 'infallible.' Aristotle is clear that in fact God has no need of the practical virtues. God is continuously active in thinking, not in paying back debts, standing up to frightening things, and exercising moderation at the dinner table (NE X.8 1178b10-19).

102 Doris (2002), 64. 
Doris is not then advocating an eliminativist line with respect to the very existence of traits of character. ${ }^{103}$ What he seeks to do rather is to posit traits that will empirically satisfy the conditional standard:

If $\mathrm{x}$ possesses character trait $\mathrm{C}$, then $\mathrm{x}$ will exhibit trait-relevant behaviour in trait-relevant eliciting conditions.

However, local traits that meet this standard will be extremely fine-grained: gunbattle-but-not-knife-fight courage must be distinguished from rifle-fire-but-not-artilleryfire courage; office-but-not-church-picnic sociability is distinct from church-picnic-butnot-office sociability; score-adding-but-not-answer-key-honesty as well as food-but-notsex-moderation, and helping-with-animals-but-not-with-humans-compassion, will be genuine local traits. ${ }^{104}$ Thus the difference between local and global traits is that the "traitrelevant eliciting conditions' will be specified very narrowly. It follows that local traits are not robust, since their consistency is proportional to the highly similar situations in which they are elicited. Nevertheless, as Doris observes,

[Local traits] underwrite substantial behavioral predictability in their narrowly specified domains; invoking them to explain behavior is a reasonable way to understand the 'contribution' of personalogical factors to behavioral outcomes without problematically inflating expectations of consistency. ${ }^{105}$

A number of features regarding Doris' proposal here will certainly strike the virtue ethicist as extremely odd. Perhaps the oddest is Doris' evident conviction that his 'fragmentation' theory of moral character is a bold and iconoclastic insight. In fact Doris catches up here to a topos that is as old as philosophy itself:

Protagoras: Well, Socrates...I maintain that all of these [wisdom, moderation, courage, justice, and piety] are parts of virtue, and four of them resemble one another fairly closely, but courage is altogether different from all the rest. And this is how you will know that what I say is true: you will find many men who are totally unjust and irreligious and wanton and ignorant, but most outstandingly courageous. (Protag. 349d)

${ }^{103}$ In this regard, he means to distinguish himself from someone like Gilbert Harman, who in Harman (2000) adopts a skeptical or eliminativist line towards the existence of character traits.

${ }^{104}$ Some of these are Doris' examples, some of them are my own.

${ }^{105}$ Doris (2002), 66. Local traits are thus 'stable', not cross-situationally consistent. 
Doris mentions in a footnote that the 'unity thesis' of virtue is 'considered "Socratic" ,. ${ }^{106}$ What he does not seem interested in however is the fact that Socrates (at least as he is portrayed in the early Platonic dialogues) does not think any human being is currently 'evaluatively integrated' with respect to his or her virtues of character. Nor does he seem to think anyone has ever been so, or will become so any time soon. We have already had occasion to note that Aristotle seems to be in at least partial agreement with this rather grim assessment: most of us, Aristotle thinks, have a lot of integrative work to do, since most of us are akratic with respect to any number of 'trait-eliciting circumstances.' If Doris had confined his attribution of globalism to common sense folk morality, these lacunae in his awareness of the virtue theoretical tradition would not be so problematic. Since he does not, he is unfortunately led to make a false stalking horse out of some of the most sophisticated thinkers who have ever inquired into the very problems he is deeply interested in.

A second oddity of Doris' account of local traits is that where any outlying attributions of cross-situational behavioural consistency do turn out to be empirically verifiable, this can only be due to the behaviour being pathological. Doris says he does not want to rule out 'pure types', such as the psychopath who fails to exhibit compassion across a wide variety of circumstances, or the melancholic who is cross-situationally depressed. Other pure types 'at the positive end of the spectrum', such as individuals who are irrepressibly upbeat, while they do not invite attributions of pathology, 'are rare enough to count as abnormal.' Doris comments that this shows that a certain amount of inconsistency in our behaviour, while it may 'confound our interpretative and ethical categories' may also be a signal of mental health. ${ }^{107}$

These remarks however only serve as further evidence that Doris has completely misunderstood what a moral disposition is taken to be in the virtue ethical tradition. Doris seems to hold out three possible psychological structures to which a moral agent may aspire. The agent may be endowed with narrow local traits. He may be cross-situationally consistent - in which case he is either pathological or ill or (at least) extremely weird. Or-

${ }^{106}$ Ibid. 178 n. 29.

${ }^{107}$ Ibid. 65. 
perhaps in addition to exhibiting some local traits, he may manifest behavioural inconsistency which, although 'confounding our ethical categories', reflects an appropriate social adaptability. ('The norms of locker rooms and luncheons', Doris intones, 'require different behaviors.') ${ }^{108}$ But as we have observed more than once, the ethical categories so confounded are not the virtue ethicist's. A trait of character for Aristotle is not a consistent disposition to a mean consistent behaviour; it is rather a mean disposition. In the context of conversational norms we may illustrate this point by appeal to the Aristotelian virtue of 'friendliness', a common rendering of the nameless virtue that Aristotle says is concerned with 'mixing with others, living in their company, sharing with them in conversations and the business of life' (NE IV.6 1126b11-12). Friendliness lies in a mean whose dimension has to do with being either pleasing or resistant, especially in conversation. The 'consistency' of the mean of friendliness (and its inconsistency in Doris' sense) is illustrated by the following passage:

This type of person seems to have to do with the pleasures and pains that come about when people mix with each other; and on occasions when it is not fine, or is harmful, to be pleasant, he will object, and will decide in favour of causing distress - so that if someone is doing something that actually brings disgrace, and no slight disgrace at that, or brings harm, and opposing it will cause little distress, the 'friendly' person will not accept it but will object. He will deal differently with eminent and ordinary people, and with people he knows better and those he knows less well, and so on for other relevant differences: he will mete out what is suitable to each set of people, preferring in itself the option of being pleasant to them, and taking care not to cause distress, but being guided by the consequences where these tip the balance the other way-and by 'consequences', I mean the fine and the advantageous. (1126b31-27a6)

To be consistently friendly or witty in Aristotle's sense then is just to behave inconsistently in Doris' sense: friendly and witty persons possess the sensitivity that recognizes the changing norms of the circumstances they find themselves in. ${ }^{109}$

A final objection I will raise to Doris' fragmentation hypothesis concerns the moral significance of the thesis. Doris anticipates the charge that the theory of local traits is of doubtful explanatory or scientific utility:

Suppose we notice that the sometimes taciturn Alberta is reliably sociable at office parties, and we therefore attribute to Alberta the local trait of office party sociability. Suppose also that this attribution grounds a successful predictive strategy - we'd do pretty well betting on Alberta to

${ }^{108}$ Ibid. 65.

${ }^{109}$ On the virtue of wittiness see NE IV.8. 
behave sociably at office parties. Now suppose you ask me why Alberta was sociable at the office party, and I respond by saying that Alberta has the trait of office party sociability. Alberta may be the life of our office parties, but I won't be if I insist on talking like this. I've invoked an explanatory strategy that looks viciously, and boringly, circular; I deduced the existence of the trait from office party behavior, then turned around and invoked the trait to explain the behavior. ${ }^{110}$

Doris' response to the charge is that attributions of broader traits are scarcely more informative; and that, in any case, there is nothing stopping us from contextualizing the attribution of local traits. The attribution to an agent of a narrow trait will naturally make appeal, Doris suggests, to the motives, goals, values, attitudes, and strategies that constitute the psychological context of the disposition in question. ${ }^{11}$

Doris presumably intends that such contextualization will result in an informative explanation of an agent's behaviour. Yet it would seem that Doris is here faced with a dilemma. Either the motives, goals, values, attitudes, and strategies so adduced are themselves extremely narrow or they are not. If only Alberta's 'office-motives', 'officegoals', and 'office-strategies' are introduced, we do not seem to have made any progress in breaking out of our explanatory circle. On the other hand, if the values, goals, and strategies, etc., to which our contextualization makes appeal include at least some of her primary values, ultimate goals, and life strategies, our explanation of her behaviour looks to be more promising. But then the question arises: why would anyone, as result of deliberating about what promotes her primary values, her ultimate goals, and her life strategies, want to develop the narrow trait of office-party-but-not-church-picnic sociability? For that matter, why would a spouse aspire to be food-but-not-sex-moderate? And why would a soldier endeavor to be gun-fight-but-not-knife-fight-courageous? If there are no good answers to these questions, then it would seem that the explanatory spade does not really turn, as Doris would have us believe, at the level of local traits.

The difficulty here is not simply that Doris has abandoned the project of providing an account of the virtues of character in favour of providing an empirically verifiable account of mere traits of character. The real problem is that the infallibly detectable traits upon which he would found his theory of character are not truly explanatory of behaviour.

${ }^{110}$ Doris (2002), 66.

${ }^{111}$ Ibid. 66. 
A virtue ethicist would locate the source of the difficulty in Doris' evident attempt to provide an account of human nature in the absence of any account of the human good. Talk of the good for man may raise anti-teleological hackles in the scientifically inclined reader (though arguably it should not); so I will attempt to clarify and defend my claim by way of an analogy that does not assume the existence of a telos for the human species qua human.

Thus suppose all human being are parents of young children, and suppose that it is the ultimate goal of all parents of young children to be good parents. Some parents however are less than excellent at the activity of parenting. The reason for this unfortunate state of affairs is, to coin a phrase, their evaluative fragmentation. John does reliable diaper duty but loses all patience when confronted with a temper tantrum. His wife Jane is unruffled by tantrums but is guiltily aware that she is vaguely ashamed of the sheer averageness of their son. John enjoys playing the fun guy role but tends to opt out of the role of disciplinarian. Jane yells at her husband in front of the kids, but she knows all the sizes of her children's shoes and knows the names and extensive biographies of all of their favorite toy animals.

If there is such a thing as being a good parent, or excellence at parenting, then if we are parents we will want to possess that excellence because it will benefit us. As rational creatures, we will want what is good for us, and so we will want to be in the good condition of being an excellent parent, because that is what we conceive to be our good.

Now suppose we are asked why Jane is disposed to know all the sizes of her children's shoes and all the names of their toys. It will hardly seem explanatory to posit a highly hyphenated narrow trait as the psychological structure that is responsible for such peculiar behaviour. On the other hand, if we 'contextualize' our explanation to include Jane's end of being a good parent, the positing of the narrow trait becomes otiose. For we can now explain Jane's narrow disposition in terms of her end: she learned the animal's names and all the shoe sizes with a view to being a good parent in the general parental domain of knowing what is going on in her children's lives. She did not-indeed it does not make sense to say - that she was guided by her end to develop the narrow trait of learning the names of soft toys. For the life of the parents of small children is constantly changing; in a month's or a year's time, such a narrow trait will be of no utility; being a 
good parent in the general domain of attention to her children's lives on the other hand will always be a trait Jane has reason to possess.

In our analogy, the virtues of parenting will therefore be broader dispositions to be guided in one's parental deliberations by a grasp of the end of being a good parent. They will include being a good parent in the domain of feeding and health care; being a good parent in the domain of discipline; being a good parent in the domain of loving attention; and so on. We may conceive of these as distinct traits, since someone who is learning to be a good parent will inevitably manifest only some of these dispositions, and to varying degrees. But it would be a mistake - an interpretative mistake - not to conceive of even these dispositions as a single general disposition to be guided in one's parenting by a partial grasp of the single end of being a good parent.

It is in precisely this sense that Aristotle conceives of the various virtuous dispositions. Virtue is the general moral disposition to act and feel in response to rational reflection upon our good. The various virtues of character are therefore simply the various ways in which we act and feel in response to the contingencies of life under the general guidance of practical wisdom and a rational understanding of our good. I have argued that Doris misunderstands this traditional conception of a moral disposition which has been inspired by Aristotle, while he is largely silent on the notions of practical wisdom and the good. A critique of virtue ethics that leaves out virtue, practical wisdom, and the good runs the risk of talking past the opposition. Insofar as Doris takes his project to constitute such a critique, I believe he has very little to say that is of interest to virtue ethics.

Carrie Swanson 


\section{Bibliography}

Annas, J. (2005) 'Comments on John Doris's Lack of character', Philosophy and Phenomenological Research 71 (3): 636-642.

Bok, H. (1996) 'Acting without choosing', Nous 30 (2): 174-96.

Burnyeat, M. (1980) 'Aristotle on learning to be good'. In Essays on Aristotle's ethics. Edited by A.O. Rorty, 69-92. Berkeley: Univ. of California Press.

Curzer, H. J. (2005) 'How good people do bad things: Aristotle on the misdeeds of the virtuous', Oxford Studies in Ancient Philosophy 28: 233-256.

Darley, J.M., and Batson, C.D. (1973) 'From Jerusalem to Jericho: A study of situational and dispositional variables in helping behavior', Journal of personality and social psychology 27: 1008. Reprinted in E. Aronson (1992), Readings about the social animal. New York: Freeman (6 $\left.{ }^{\text {th }} \mathrm{ed}.\right)$, $37-51$.

Doris, J.M. (2002) Lack of character. Cambridge: Cambridge University Press.

Doris, J.M. (2009) 'Skepticism about persons’, Philosophical Issues 19 (1): 57-91.

Dow, J. (2011) 'Aristotle's theory of the emotions: emotions as pleasures and pains'. In Moral psychology and human action in Aristotle. Edited by M. Pakaluk and G. Pearson, 47-74. Oxford: Oxford University Press.

Doyle, A.C. (1924) Memories and adventures. Boston: Little, Brown, \& Company.

Flanagan, O. (1991) Varieties of moral personality: ethics and psychological realism. Cambridge, Mass.: Harvard University Press.

Gilbert, S.J. (1981) 'Another look at the Milgram obedience studies: the role of the graduated series of shocks', Personality and social psychology bulletin 7: 690-5.

Goldhagen, D.J. (1996) Hitler's willing executioners: ordinary Germans and the Holocaust. New York: Knopf.

Harman, G. (2000) 'Moral philosophy meets social psychology: virtue ethics and the fundamental attribution error'. In Explaining value and other essays in moral philosophy G. Harman, 165-78. Oxford: Oxford University Press.

Irwin, T. (1985) 'Permanent happiness: Aristotle and Solon', Oxford Studies in Ancient Philosophy 3: 89-124.

Irwin, T. (2000) 'Ethics as an inexact science: Aristotle's ambitions for moral theory'. In Moral particularism. Edited by B. Hooker and M. Little, 130-156. Oxford: Clarendon Press.

Isen, A.M., and Levin, P.F. (1972) 'Effect of feeling good on helping: cookies and kindness, Journal of personality and social psychology 21: 384-8.

Kamtekar, R. (2004) 'Situationism and virtue ethics on the content of our character', Ethics 114: 458-491.

Lawrence, G. (2011) 'Acquiring character: becoming grown-up'. In Moral psychology and human action in Aristotle. Edited by M. Pakaluk and G. Pearson, 233-283. Oxford: Oxford University Press.

Lear, G. (2009) 'Aristotle on moral virtue and the fine'. In The Blackwell guide to Aristotle's Nicomachean Ethics. Edited by R. Kraut, 116-136. Malden, MA: Blackwell. 
Leunissen, M. (2017) 'Aristotle on the person-situation debate: from natural character to moral virtue'. In Questions of character. Edited by Iskra Fileva, 33-45. Oxford: Oxford University Press.

McDowell, J. (1979) 'Virtue and reason', Monist 62: 331-50.

McDowell, J. (1998) 'Some issues in Aristotle's moral psychology'. In Cambridge Companion to Ancient Thought 4: Ethics. Edited by S. Everson, 107-128. Cambridge: Cambridge University Press.

Milgram, S. (1963) 'Behavioral study of obedience', Journal of abnormal and social psychology 67: 371-8.

Penner, T. (1973) 'The Unity of Virtue', Philosophical Review 82 (1): 35-68.

Reeve, C.D.C. (1992) Practices of reason. Aristotle's Nicomachean Ethics. Oxford: Clarendon Press.

Ross, L. (1988) 'Situationist perspectives on the obedience experiments', Contemporary psychology 33: 101-4.

Shiner, R. (1979) 'Ethical perception', Apeiron 13: 79-85.

Sreenivasan, G. (2002) 'Errors about errors: virtue theory and trait attribution', Mind 111: 47-68.

Twain, M. (1996) Adventures of Huckleberry Finn. New York: Oxford University Press.

Tuozzo, T. (1995) 'Contemplation, the noble and the mean: the standard of moral virtue in Aristotle's ethics', Apeiron 28 (4): 129-154.

Wiggins, D. (1980) 'Deliberation and practical reason'. In Essays on Aristotle's ethics. Edited by A. Rorty, 221-240. Berkeley: University of California Press.

Woods, M. (1986) 'Intuition and perception in Aristotle's ethics', Oxford Studies in Ancient Philosophy 4: 145-66. 